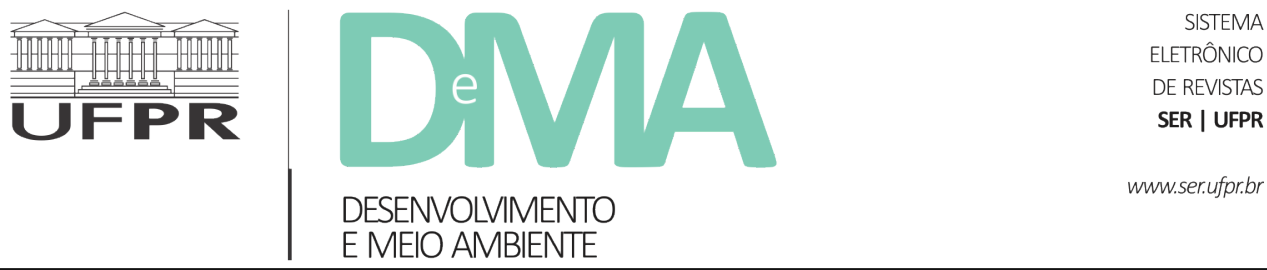

\title{
O legado de Chico Mendes: êxitos e entraves das Reservas Extrativistas
}

\section{The Legacy of Chico Mendes: successes and obstacles in the Extractive Reserves}

\author{
Mauro W. BARBOSA DE ALMEIDA ${ }^{1 *}$, Mary Helena ALLEGRETTI ${ }^{2}$, Augusto POSTIGO ${ }^{3}$ \\ ${ }^{1}$ Universidade Estadual de Campinas (Unicamp), Campinas, SP, Brasil. \\ 2 Instituto de Estudos Amazônicos, Curitiba, PR, Brasil. \\ ${ }^{3}$ Instituto Socioambiental (ISA), São Paulo, SP, Brasil. \\ "E-mail de contato: maurowbalmeida@gmail.com
}

Artigo recebido em 13 de julho de 2018, versão final aceita em 16 de outubro de 2018.

RESUMO: O conceito de Reservas Extrativistas foi criação de seringueiros amazônicos, e Chico Mendes, com o apoio de aliados urbanos que deram visibilidade ao programa em escala nacional e internacional, propagando a ideia nas comunidades da floresta. As Reservas Extrativistas foram propostas para reconhecer direitos de moradores da floresta a territórios tradicionalmente ocupados e manter as florestas que são a base de seu modo de vida (Allegretti, 1990). Com esse programa, seringueiros, caboclos e ribeirinhos, habitantes da Amazônia até então invisíveis e residuais (Parker, 1985; Allegretti, 1979; Teixeira, 1980; Barbosa de Almeida, 1990; Nugent, 1993; Adams et al., 2006), ganharam rosto e, numa reviravolta da história, começaram a ter voz sobre seus destinos (Carneiro da Cunha \& Barbosa de Almeida, 2000). O programa pelo qual lutou Chico Mendes fez diferença. Trinta anos após seu assassinato, há no Brasil 94 Reservas Extrativistas que integram o sistema nacional de Unidades de Conservação, abrangendo um território total de 15 milhões e 500 mil hectares, além de 381 Assentamentos Extrativistas no âmbito do programa de Reforma Agrária, abrangendo 10,8 milhões de hectares. Nesses 26 milhões de hectares $(260.000 \mathrm{~km} 2)$ moram seringueiros e castanheiros, quilombolas, coletores de molusco, pescadores artesanais e outros camponeses que têm em comum baixíssimo impacto ambiental, conservando e ampliando a diversidade de culturas e técnicas do país. Reservas Extrativistas são florestas (e outros biomas) com alta biodiversidade habitadas por populações com baixa densidade demográfica que utilizam técnicas de baixa intensidade. As Reservas Extrativistas visam conciliar direitos territoriais e diversidade cultural com a conservação e aumento da biodiversidade.

Palavras-chave: Chico Mendes; Reservas Extrativistas; reforma agrária; biodiversidade; desmatamento; governo local. 
ABSTRACT: The idea of Extractive Reserves is a creation of Amazonian forest dwellers, and Chico Mendes, with the support of urban allies who gave visibility to the rubber tapper's program on a national and international scale, promoting the idea within the forest communities. Extractive Reserves were proposed to recognize the rights of forest dwellers to traditionally occupied territories and to maintain the forests that are the basis of their way of life (Allegretti, 1990). With this program, seringueiros, caboclos and riparinos, previously invisible and residual inhabitants of the Amazon (Parker, 1985; Allegretti, 1979; Teixeira, 1980; Barbosa de Almeida, 1990; Nugent, 1993; Adams et al., 2006), gained a face and, in a turnaround of history, began to have a voice about their destinies (Carneiro da Cunha \& Barbosa de Almeida, 2000). The program for which Chico Mendes fought made a difference. Thirty years after its assassination, there are in Brazil 94 Extractive Reserves that integrate the National System of Conservation Units, covering a total territory of 15 million and 500 thousand hectares, and 381 Extractivist Settlements under the Agrarian Reform program, covering 10, 8 million hectares. In these 26 million hectares $(260,000 \mathrm{~km} 2)$ there are rubber tappers and Brazil nut collectors, maroons, mollusc collectors, artisanal fishermen and other peasants who have in common extremely low environmental impact, conserving and expanding the diversity of cultures and techniques of the country. Extractive Reserves are forests (and other biomes) with high biodiversity inhabited by populations with low demographic density that use low intensity techniques. Extractive Reserves aim to reconcile territorial rights and cultural diversity with the conservation and increase of biodiversity.

Keywords: Chico Mendes; Extractive Reserves; land reform; biodiversity; deforestation; local governance.

\section{Um conceito novo}

A Reserva Extrativista é a reforma agrária dos seringueiros. É o reconhecimento de áreas de floresta, ocupadas tradicionalmente por seringueiros e outros extrativistas, como áreas de domínio da União, com usufruto exclusivo dos seringueiros organizados em cooperativas ou associações. Nas Reservas Extrativistas, não há títulos individuais de propriedade. Nelas serão respeitadas a cultura e as formas tradicionais de organização e de trabalho dos seringueiros, que continuarão a realizar a extração de produtos de valor comercial como a borracha, a castanha e muitos outros, bem como a caça e a pesca não predatórias, juntamente com pequenos roçados de subsistência em harmonia com a regeneração da mata. As Reservas Extrativistas não serão áreas inviáveis economicamente: garantida a floresta, os seringueiros organizados aumentarão a produtividade, introduzindo inovações tecnológicas adequadas. Além disso, darão continuidade à criação de escolas, postos de saúde e cooperativas geridas por seringueiros. A Reserva Extrativista não é apenas a reforma agrária dos seringueiros, mas também uma forma de preservação da natureza pelos que dela dependem, e uma alternativa econômica para a Amazônia. (STR/CNS/CUT, 1989, p. 16).
Lévi-Strauss escreveu que, ao lado das Terras Indígenas, as Reservas Extrativistas poderiam constituir a melhor esperança para salvar a Amazônia, ao mesmo tempo em que destacou a originalidade do conceito (Lévi-Strauss, 2003). Essa originalidade continua a provocar estranheza trinta anos depois do assassinato de Chico Mendes. De fato, o programa das Reservas Extrativistas foi criticado por dois campos desde sua implementação. De um lado, conservacionistas veem em territórios tradicionalmente habitados o risco da erosão de florestas e de biodiversidade (Redford, 1992; Peres, 2000), ou desconfiam da capacidade de povos tradicionais para governar no futuro territórios que conservaram no passado (Brandon et al., 1988). Do lado oposto, agrônomos desenvolvimentistas veem nas Reservas Extrativistas um bloqueio para a intensificação agrícola por agricultores familiares (Homma, 1993). Ao lado desses críticos, há pressões repetidas para reduzir Reservas Extrativistas ou convertê-las em 
“Áreas de Proteção Ambiental”, de modo a permitir fazendas e outros agronegócios (CONFREM/CNS/ IEA, 2018).

O conceito de Reservas Extrativistas desafiou a visão unilinear de desenvolvimento apoiada na intensificação tecnológica cujo componente principal seria a substituição de técnicas extrativistas pela domesticação e, em seguida, pela bioengenharia; além disso, desafiou a visão conservacionista paradigmática que defendia a separação estrita de humanos e de ecossistemas como requisito necessário para a conservação da diversidade biológica e dos serviços ambientais prestados por ecossistemas como florestas tropicais, manguezais e outros; finalmente, contestou a visão segundo a qual a justiça social e a luta contra a pobreza deveriam ter como eixo exclusivo o incremento da produção agrícola familiar.

Face a essas concepções arraigadas até a década de 1980, é notável que trabalhadores florestais amazônicos, e não intelectuais, tenham formulado um novo paradigma que articula as metas da justiça social e da conservação da diversidade cultural e ambiental.

O conceito de Reserva Extrativista surgiu de um movimento social amazônico que tomou corpo na década de 1980, combinando reivindicações de seringueiros e castanheiros expulsos de seus territórios tradicionais, à resistência contra a destruição das florestas em que viviam e das quais obtinham a vida. Essa ação coletiva de seringueiros, de maneira imprevista, articulou-se a movimentos sociais globais contra a destruição das florestas (Barbosa de Almeida, 2004a). Isso não foi tudo, no entanto, porque os sindicalistas que resistiram à destruição de florestas de seringueiras e castanheiras reivindicaram direitos a Reservas Extrativistas - territórios assegurados a seringueiros, sem divisão em lotes e com um mínimo de 300 ha e um máximo de 500 ha por colocação, obedecendo à realidade extrativista da região. Em dezembro de 1987, o Conselho Nacional dos Seringueiros (CNS) decidiu que as Reservas Extrativistas deveriam ser terras públicas com usufruto exclusivo de moradores tradicionais, seguindo o modelo das Terras Indígenas como o único regime que impediria a reconcentração de terras pela especulação fundiária e o agronegócio.

"Não queremos título de propriedade da terra, queremos que ela seja da União, com usufruto dos seringueiros" (Chico Mendes, em STRX/CNS/CUT, 1989, p. 8).

Porque Terras da União com usufruto de comunidades locais, e não títulos individuais de propriedade? Esse componente essencial da ideia de Reservas Extrativistas, também presente no conceito de Reservas de Desenvolvimento Sustentável e nos Assentamentos Agroextrativista, foi resultado da experiência de sindicatos e associações de seringueiros durante a década de 1970 e de 1980, que viam a sistemática reconcentração de terras em áreas de reforma agrária. Esse processo era particularmente agudo em seringais, onde bastava que um seringueiro-posseiro vendesse sua posse florestal para que todo o entorno fosse degradado pelo desmatamento e plantio, o que levava a um efeito-dominó que expulsava todos os demais ocupantes. A solução dos sindicalistas seringueiros para essa dinâmica perversa foi imitar o exemplo das Reservas Indígenas, que eram inalienáveis porque permaneciam parte do patrimônio nacional.

Chico Mendes foi o paladino das Reservas Extrativistas, não somente porque criou a Reserva Extrativista do Seringal Cachoeira, mas sobretudo 
porque defendeu o conceito como modalidade de regulamentação territorial na Amazônia e no Brasil. Mostrou assim a ousadia política e intelectual em dois quesitos: primeiro, recusando o modelo de títulos de propriedade individual sobre lotes; segundo, afirmando direitos de ocupação tradicional sobre territórios utilizados de maneira extrativista e não apenas agrícola (Allegretti, 2008).

As Reservas Extrativistas, Reservas de Desenvolvimento Sustentável e Assentamentos Agroextrativistas, ao lado das Terras Indígenas e das Terras de Quilombo, constituem uma parte importante do regime territorial no Brasil, por assegurarem direitos coletivos para populações que ocupam tradicionalmente biomas de importância nacional: são seringueiros e castanheiros, pescadores artesanais, coletores de babaçu, ervateiros de faxinais, coletores de berbigão, entre outras. O qualificativo de "tradicional" significa que essas comunidades têm utilizado os recursos do território com tecnologias de baixo impacto. Em vez de "atrasadas", essas técnicas devem ser vistas como eficientes para a conservação. O reconhecimento de territórios tradicionalmente ocupados sob regimes de uso comunitário tradicional significa pluralismo territorial: terras públicas em usufruto por comunidades situam-se entre a propriedade privada de indivíduos ou empresas e terras públicas geridas diretamente pelo Estado.

\section{Resultados territoriais}

De 1990 até 2018 haviam sido criadas 94 Reservas Extrativistas (das quais 66 federais e 28 estaduais), e 36 Reservas de Desenvolvimento Sustentável (das quais 2 federais, 29 estaduais e 5 municipais), perfazendo $240.462 \mathrm{~km}^{2}$ ou $24,0 \mathrm{mi}-$ lhões de hectares. Além disso, desde 1987 foram criados 381 Assentamentos Agroextrativistas, com área de $108.500 \mathrm{~km}^{2}$, ou seja, 10,8 milhões de hectares. O que, somado aos 24,0 milhões de hectares de Reservas Extrativistas e RDS dá 34,8 milhões de hectares (Tabela 1).

TABELA 1 - Reservas Extrativistas, Reservas de Desenvolvimento Sustentável e Assentamento Extrativistas (1990-2018).

\begin{tabular}{|c|c|c|c|c|}
\hline Unidades de Conservação & Número & $\begin{array}{l}\text { Subtotais } \\
\text { (número) }\end{array}$ & $\begin{array}{l}\text { Área (milhões de } \\
\text { ha) }\end{array}$ & Subtotais (áreas) \\
\hline RESEX Federais & 66 & & 13,4 & \\
\hline RDS Federais & 2 & & 0,1 & \\
\hline RDS Estaduais & 29 & & 8,5 & \\
\hline SUBTOTAL Resex e RDS & 130 & & 24,0 & \\
\hline Assentamentos Agroextrativistas & 381 & & 10,8 & 34,9 \\
\hline TOTAL & 641 & & 34,8 & \\
\hline
\end{tabular}

FONTE: ICMBIO (2018); INCRA (2018). 
Dois governos concentraram o maior número de Reservas Extrativistas criadas, o de Fernando Henrique Cardoso e o de Luiz Inácio Lula da Silva, tanto em número de unidades criadas quanto em área total, representando $75,7 \%$ do total. Entretanto, em área total protegida e número de unidades, foi durante o governo Lula que essa modalidade de unidade de conservação se consolidou, com 53\% da área total e $42 \%$ do número de unidades. Observando a relação entre número de unidades criadas e área total protegida, por período governamental, percebe-se que as quatro primeiras Resex, criadas em 1990, no governo Sarney, apresentam um resultado que não foi superado nas décadas seguintes (média de 541 mil hectares por unidade).

TABELA 2 - Criação de Reservas Extrativistas Federais por Governo 1990-2018.

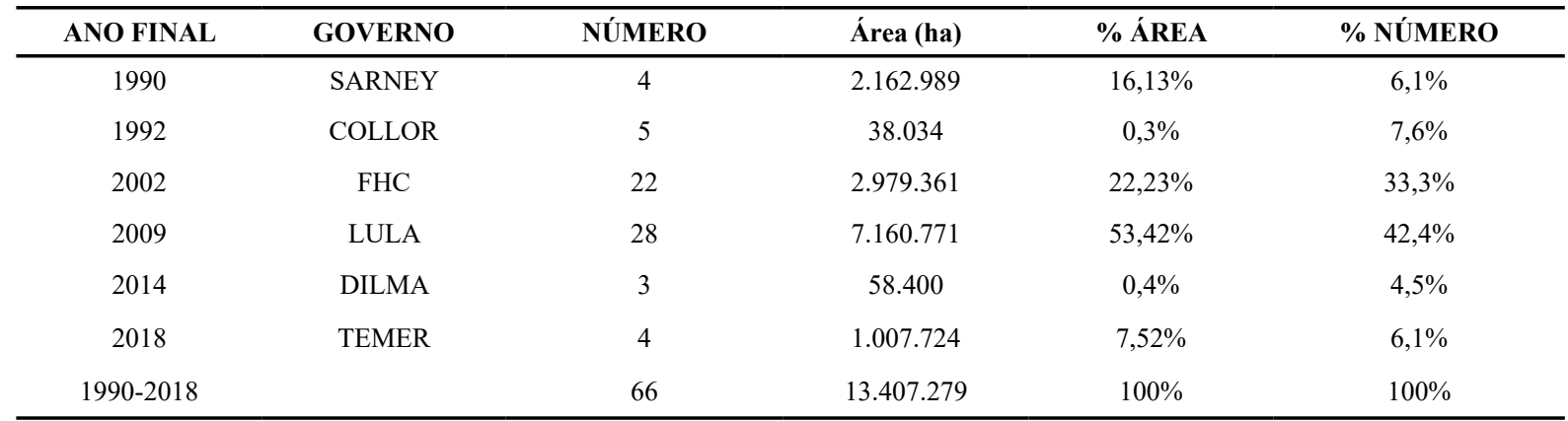

FONTE: ICMBio (2018); ISA (2018).

\section{Efeitos sobre desmatamento}

Publicações recentes têm afirmado que as Reservas Extrativistas não contribuem para a conservação de florestas e que, ao contrário, ocorre nelas aceleração do desmatamento. Essa afirmação é apoiada na análise de dois casos: a Reserva
Extrativista do Alto Juruá e a Reserva Extrativista Chico Mendes, ambas no Estado do Acre (Alencar et al., 2016; Freitas et al., 2018). Vamos tratar do tema primeiramente com base nos dados de Alencar, tratando das quatro primeiras Reservas Extrativistas criadas em 1990. Vê-se pelos dados de Alencar et al. que, partindo do patamar de 1999, as taxas de

TABELA 3 - Evolução da área desflorestada de 1999 a 2015 em \% da área total.

\begin{tabular}{cccccc}
\hline Ano & Chico Mendes & Alto Juruá & Rio Ouro Preto & Rio Cajari & 4 Reservas \\
\hline 1999 & $2,1 \%$ & $1,3 \%$ & $3,8 \%$ & $1,5 \%$ & $1,9 \%$ \\
2004 & $1,9 \%$ & $0,9 \%$ & $3,8 \%$ & $0,2 \%$ & $1,4 \%$ \\
2009 & $0,7 \%$ & $0,3 \%$ & $1,4 \%$ & $0,4 \%$ & $0,6 \%$ \\
2015 & $0,9 \%$ & $0,7 \%$ & $0,7 \%$ & $0,2 \%$ & $0,7 \%$ \\
\hline
\end{tabular}




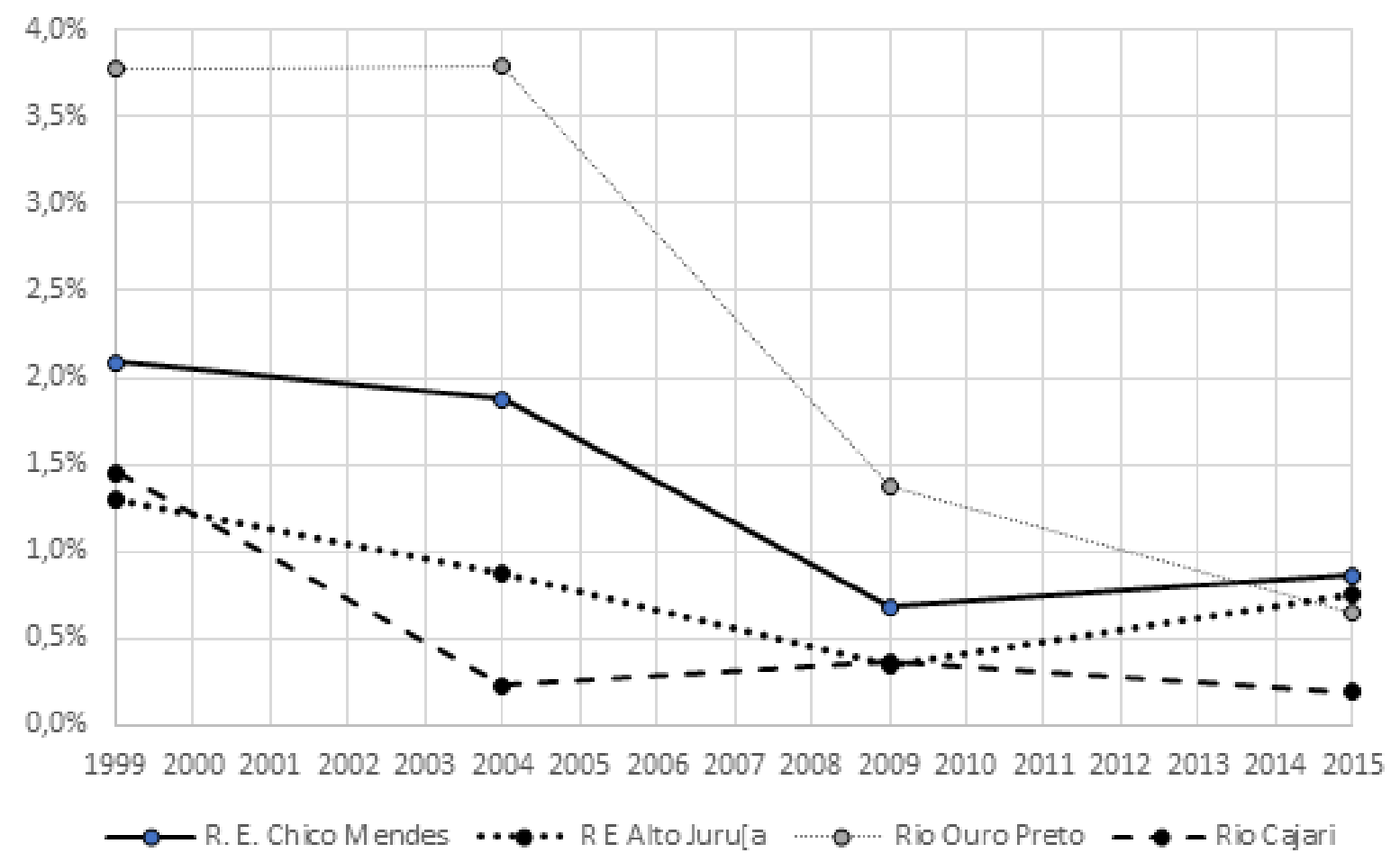

FIGURA 1 - Desmatamento nas 4 primeiras reservas, 1990-2015 em \% da área total.

FONTE: Alencar et al. (2016).

desmatamento nas quatro primeiras Reservas Extrativistas no período de 2000 a 2015 ficam abaixo de $1 \%$ em todas elas e têm uma tendência declinante (com um aumento de 2009 a 2015 nas Reservas Chico Mendes e Alto Juruá).

Esses dados não corroboram a visão catastrófica sugerida por Freitas et al. (2018) e indicam uma tendência linear para a redução das taxas de desmatamento em todas as reservas criadas em
19901. Convém ainda utilizar a série de dados do PRODES, para o período de 2008 a 2017, abrangendo cinco Reservas Extrativistas do Estado do Acre.

Os dados confirmam que a Reserva Extrativista Chico Mendes de fato apresentou uma tendência ascendente em taxas de desmatamento de 2009 a 2016, ano a partir do qual essa tendência se inverte. Mas pode-se notar que essa tendência aparece como uma exceção no conjunto das cinco Reservas

\footnotetext{
${ }^{1}$ Houve de fato expansão da área dedicada à pecuária nas Reservas Extrativistas do Alto Juruá e Chico Mendes na década de 1990, após a criação das Reservas. Uma explicação para o fato é que, ao lado do fim dos preços administrados para a borracha, direitos territoriais estimularam a sedentarização e a capitalização na forma de pequenos rebanhos. No Alto Juruá há indícios de que essa tendência foi interrompida a partir de 2010, à medida que o retorno do investimento em cultivo de frutas e hortaliças ao lado da produção tradicional de farinha, tabaco e açúcar-gramixó, mostrou-se mais rentável do que a criação de gado (Emperaire \& Barbosa de Almeida, 2012).
} 
TABELA 4 - Desmatamento anual em Reservas Extrativistas do Acre, 2008-2017 (em hectares).

\begin{tabular}{|c|c|c|c|c|c|}
\hline ANO & Alto Juruá & Chico Mendes & $\begin{array}{c}\text { Riozinho } \\
\text { da Liberdade }\end{array}$ & $\begin{array}{c}\text { Alto } \\
\text { Tarauacá }\end{array}$ & $\begin{array}{l}\text { Cazumbá- } \\
\text { Iracema }\end{array}$ \\
\hline 2008 & 794 & 1.155 & 151 & 311 & 93 \\
\hline 2010 & 1.948 & 710 & 315 & 327 & 285 \\
\hline 2011 & 796 & 1.209 & 65 & 232 & 282 \\
\hline 2013 & 155 & 1.123 & 63 & 23 & 194 \\
\hline 2014 & 595 & 2.224 & 39 & 175 & 155 \\
\hline 2015 & 125 & 3.232 & 211 & 88 & 205 \\
\hline 2016 & 225 & 3.391 & 154 & 41 & 271 \\
\hline
\end{tabular}

FONTE: PRODES (2018); ISA (2018).

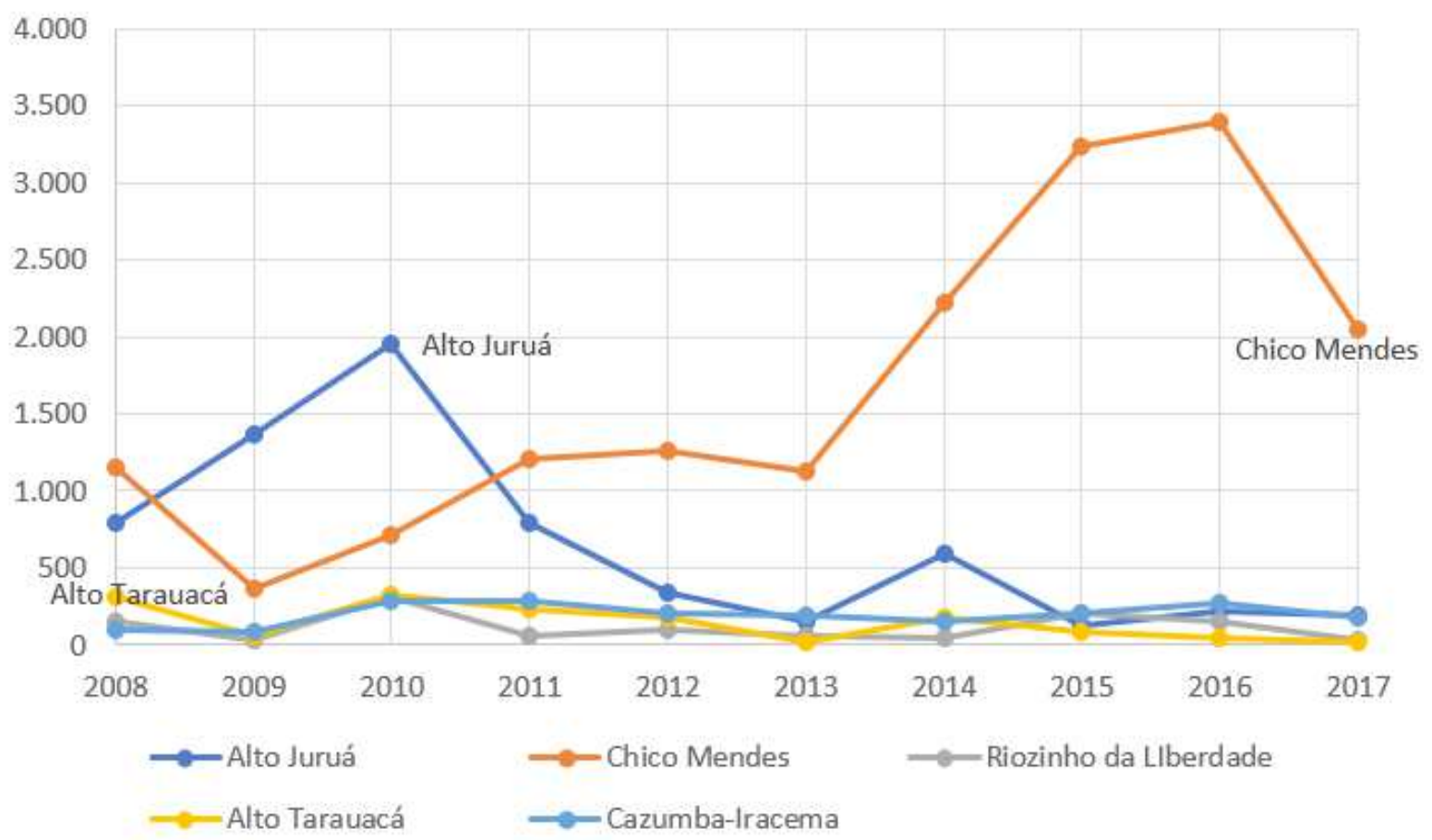

FIGURA 2 - Desmatamento em 5 Reservas Extrativistas do Acre, 2017-2018 (hectares).

FONTE: PRODES (2018); ISA (2018). 


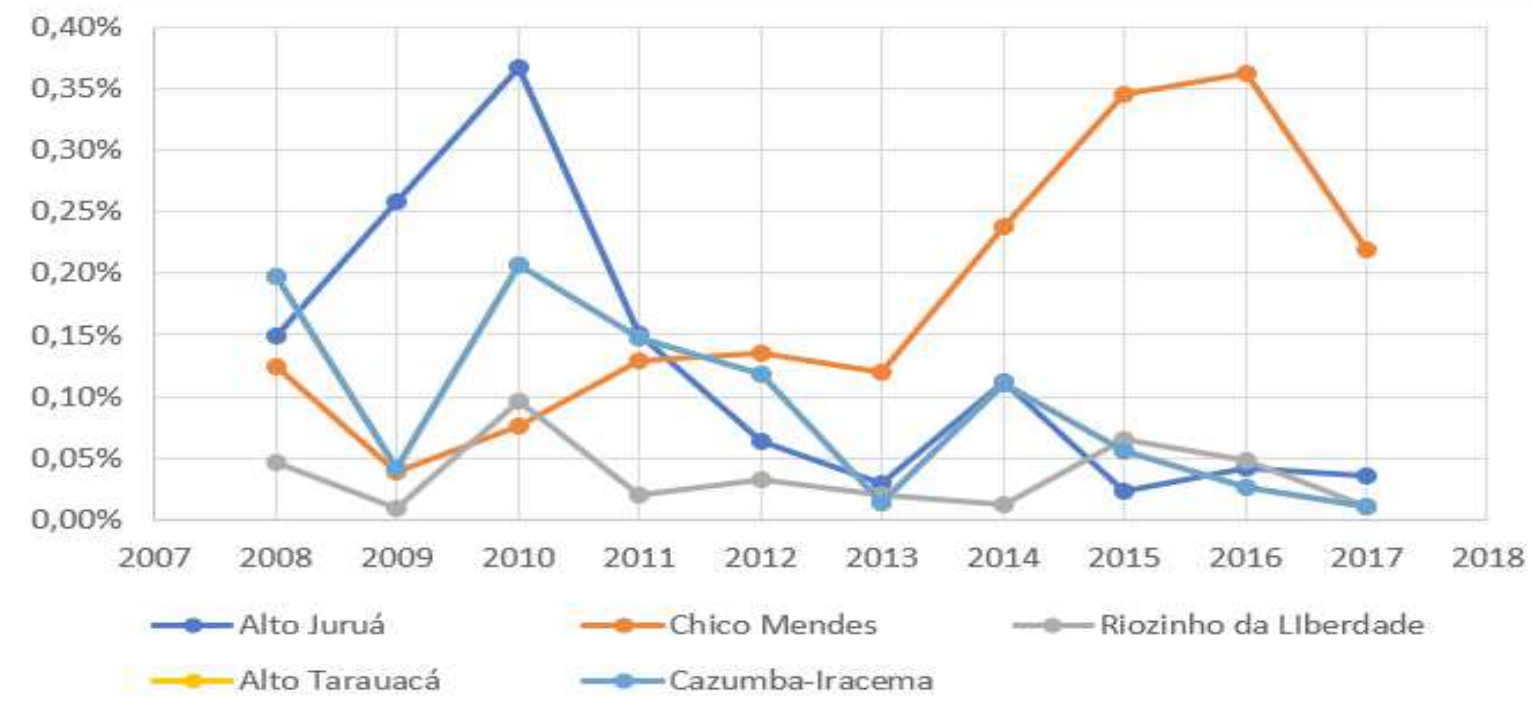

FIGURA 3 - Área desmatada anual em 5 Resex do Estado do Acre, em \% da área 2008-2017 (em hectares). FONTE: PRODES (2018).

do Estado. Esse ponto é corroborado pelos dados apresentados em forma de porcentagens da área desmatada sobre as áreas totais de cada Reserva.

Vê-se que o caso da Reserva Chico Mendes é anômalo, e que nas demais Reservas do estado do Acre os índices de desmatamento anual convergem para uma taxa média inferior a $0,06 \%$ da área total. Esse índice e essa tendência são corroborados pela consideração do conjunto das Reservas Extrativistas federais do Bioma Amazônia no período de 2008-2017.

Em face desses dados, parece claro que a Reserva Extrativista Chico Mendes não indica uma tendência geral do conjunto das Reservas Extrativistas. Esse ponto fica ainda mais evidente quando consideramos as 41 Reservas Extrativistas do Bioma Amazônia em um gráfico cuja finalidade é sugerir que a Reserva Chico Mendes se comporta como caso desviante.
Os dados para o conjunto das Reservas, seja na escala do estado do Acre, seja para o bioma amazônico como um todo, indicam que as taxas de desmatamento nas Reservas Extrativistas são declinantes e convergem para taxas abaixo de 0,10 tanto no Estado do Acre (com a única exceção da Resex Chico Mendes) como no Bioma Amazônia como um todo.

Sobre o caso da Resex Chico Mendes, a interpretação visual das áreas afetadas pelo desmatamento (não incluída aqui) leva a que (a) o efeito de desmatamento ocorre sobretudo na faixa contínua à fronteira entre a Reserva e as fazendas da sua borda leste, e que, portanto, (b) essa faixa de fronteira a leste da reserva opera como uma barreira para a expansão das fazendas.

Finalmente, é relevante mencionar a seguinte passagem de um estudo abrangente que compara 


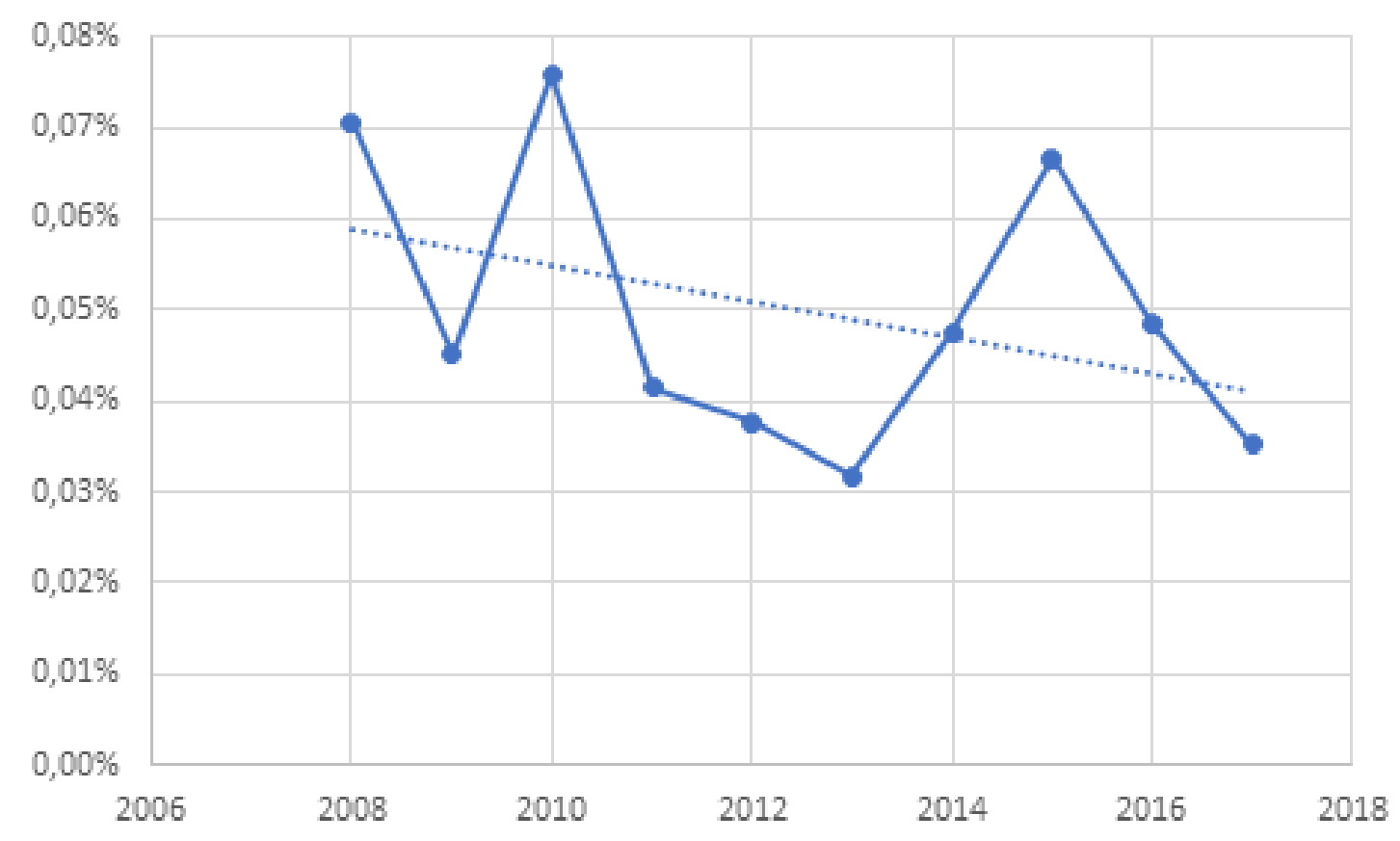

FIGURA 4 - Desmatamento em Reservas Extrativistas no Bioma Amazônia (em \%) 2008-2017.

FONTE: PRODES (2017). Médias de taxas anuais de desmatamento (excluindo casos sem dados de desmatamento) para 50 Reservas Extrativistas Federais do Bioma Amazônia. (Ver Tabela anexa ao artigo).

TABELA 5 - Área desmatada anualmente em 50 Resex de 2008-2017 (em hectares e \%) de área desmatada.

\begin{tabular}{ccc}
\hline ANO & DESMATAMENTO (HECTARES) & DESMATAMENTO (EM \%) \\
\hline 2008 & $8.300,84$ & $0,07 \%$ \\
2009 & $5.300,25$ & $0,05 \%$ \\
2010 & $8.933,67$ & $0,08 \%$ \\
2011 & $4.875,81$ & $0,04 \%$ \\
2012 & $4.437,07$ & $0,04 \%$ \\
2013 & $3.734,49$ & $0,03 \%$ \\
2014 & $5.600,04$ & $0,05 \%$ \\
2015 & $7.836,65$ & $0,07 \%$ \\
2016 & $5.720,22$ & $0,05 \%$ \\
2017 & $4.139,32$ & $0,04 \%$ \\
\hline
\end{tabular}

FONTE: PRODES 2017. Médias de taxas anuais de desmatamento (excluindo casos sem dados de desmatamento) para 50 Reservas Extrativistas Federais do Bioma Amazônia. 
efeitos de assentamentos agrícolas sem componentes ambientais com assentamentos extrativistas:

Os projetos de assentamento convencionais, representados principalmente pela categoria conhecida pela sigla PA (Projeto de Assentamento), são a modalidade de assentamento de reforma agrária que mais converteu suas florestas em outros usos da terra na Amazônia. Essa modalidade hoje agrega $82 \%$ do desmatamento acumulado dentro dos assentamentos da região. Por outro lado, os assentamentos categorizados como ambientalmente diferenciados e aqueles relacionados ao reconhecimento de populações tradicionais (i.e. Projetos de Assentamento Florestal - PAF, Extrativista - PAE, e de Desenvolvimento Sustentável - PDS), são os que menos têm contribuído para a conversão de florestas em outros usos da terra, contabilizando somente $7 \%$ do desmatamento que ocorreu dentro dos assentamentos da região. Esse fato sugere que o investimento na consolidação dos assentamentos ambientalmente diferenciados pode representar avanços na redução do desmatamento dentro dos assentamentos (Alencar et al., 2016).

Reservas Extrativistas e Assentamentos Extrativistas contribuem de fato para a manutenção de florestas e redução do desmatamento.

\section{Efeitos sobre a biodiversidade}

\subsection{Impacto sobre a fauna cinegética}

Conservacionistas, e especialmente biólogos especializados em mamíferos, veem territórios tradicionais como ameaça a grandes mamíferos, porque são os animais visados pelos caçadores indígenas e camponeses: antas, veados, caititus, queixadas; e também pacas e capivaras; e, finalmente cotias e quatipurus, além de guaribas (Allouata sp.) e outros grandes primatas, e cracídeos (nambus, mutuns). Segundo a fórmula de Kent Redford, não basta conservar florestas, porque florestas habitadas por caçadores são "florestas vazias" (Redford, 1992).

Essa argumentação faz sentido em áreas como as cabeceiras do rio Tejo na Reserva Extrativista do Alto Juruá na década de 1980, onde o seringal Riozinho da Restauração, com cerca de 30.000 hectares e 70 grupos domésticos, possuía uma densidade demográfica de aproximadamente 1,4 habitantes por $\mathrm{km}^{2}$. O efeito disso era a reputação do Riozinho da Restauração como "rio da fome" na década de 1980, isto é, onde seringueiros não obtinham caça. O Riozinho da Restauração constituía 5,7\% da área total da Reserva e precisamente a zona mais produtiva e mais densamente habitada. De fato no Riozinho da Restauração, área de máxima concentração de seringueiros, a caça era escassa - onças eram raras, assim como antas e porcos-do-mato, caititus e queixadas. A densidade demográfica, um dos fatores importantes de pressão sobre a fauna, varia entre níveis baixíssimos na Reserva Extrativista Riozinho do Anfrísio, com 0,07 hab./ $/ \mathrm{km}^{2}$, níveis baixos (de $0,38 \mathrm{hab} . / \mathrm{km}^{2}$ ) na Reserva Extrativista do Rio Xingu a $0,81 \mathrm{hab} . / \mathrm{km}^{2}$, na Reserva Extrativistas da Terra do Meio (ISA, 2016; ICMBio 2018), enquanto na Reserva Extrativista Chico Mendes a densidade demográfica chegava em 2014 a 1,2 hab./ $\mathrm{km}^{2}$ (Brasil, 2006). Essas diferenças são indicadores da pressão sobre a fauna cinegética.

O ponto importante a salientar é que o extrativismo - vegetal ou animal - induz uma distribuição da população caracterizada por baixas densidades e pequenos grupos habitacionais afastados entre si (Murphy \& Steward, 1956). Essa formulação é apoiada pelo estudo da Reserva Extrativista do Alto Juruá. Nesse território, a densidade de colocações ocupadas por seringueiros e suas famílias na década de 1980 refletia a densidade e a produtividade das 
estradas de seringa, levando a manchas de maior densidade demográfica (rio Bagé, rio Tejo) e a zonas de baixa densidade (interflúvios entre rio Tejo e rio São João). Como consequência, a abundância de caça variava muito. Em resumo, havia zonas com pressão sobre a caça e áreas com abundância de caça, que operavam como "fonte" e "sumidouro", conforme dados de esforço e retorno coletados por seringueiros (Novaro et al., 2000; Ramos, 2005; Barbosa de Almeida et al., 2016).

A densidade demográfica para a Reserva do Alto Juruá era aproximadamente de 1,0 habitante por $\mathrm{km}^{2}$ (5.394 moradores recenseados em $1991 \mathrm{em}$ um território de $5.000 \mathrm{~km}^{2}$ ), mas localmente essa densidade era de 1,4 hab. $/ \mathrm{km}^{2}$ na bacia do Riozinho (com $300 \mathrm{~km}^{2}$ e 69 colocações de seringa ocupadas), um "sumidouro" onde as colocações eram distribuídas como "grãos de areia" jogados ao acaso conforme a feliz expressão do prof. Keith S. Brown Jr., da Universidade Estadual de Campinas. Em compensação, a bacia do Paraná do Machadinho, último afluente do Tejo, tinha baixíssima densidade demográfica concentrada linearmente na margem do paraná e farta abundância de caça, constituindo uma "fonte".

A conclusão preliminar dessas observações é que a pressão da população extrativista sobre a população de animais silvestres, que é objeto de atividade cinegética, tende a ser baixa ou muito baixa onde a densidade populacional é muito baixa (na ordem de magnitude de $0,1 \mathrm{hab} . / \mathrm{km}^{2}$ a $1,0 \mathrm{hab} . /$ $\mathrm{km}^{2}$ ) e onde há separação entre zonas de "coleta" e zonas de "regeneração" (e.g. áreas próximas a vias de acesso como rios e estradas, e áreas fora da zona de exploração habitual). Mas isso não é tudo. Raramente estudos de pressão de caça levam em conta fatores institucionais, como a presença ou ausência de comercialização de animais silvestres (como alimento, peles, dentes, penas etc.), e a presença ou ausência de regras costumeiras ou institucionalizadas (e.g. tabus de consumo e planos de manejo). Em Reservas Extrativistas, atividades agrícolas, pecuárias e de coleta animal e vegetal, em princípio, deveriam ser reguladas por estatutos considerados como legítimos pelas comunidades (Barbosa de Almeida \& Pantoja, 2004b).

Todas as espécies de primatas com ocorrência registrada no Sudoeste Amazônico (Emmons \& Feer, 1990; Eisenberg \& Redford, 1999) são conhecidas pelos moradores da Reserva Extrativista do Alto Juruá (Conceição \& Barbosa de Almeida, 1995). Por outro lado, tanto entrevistas como diários de caça indicam que indivíduos dos gêneros Lagothrix sp., Ateles sp., respectivamente barrigudo e macaco-preto, são localmente extintos nas zonas habitadas por seringueiros, e foram observados apenas nas zonas de refúgio e nas fronteiras da reserva (Peres 2015). Paradoxalmente, o etnogênero guariba (Alouatta sp., capelão no caso do macho), apesar de ser territorial e facilmente localizável pela vocalização, mostra grande resiliência mesmo próximo de comunidades humanas. Soins (gêneros Callitrichidae e Callimoniconidae) habitam capoeiras, mas não são alvo de predação humana. Esses dados, resultantes da atividade de pesquisadores seringueiros, corroboram a importância da colaboração de moradores para o monitoramento da pressão cinegética (Parry \& Peres, 2015; Van Vliet et al., 2015, Shepard et al., 2012). 


\subsection{Indicadores de biodiversidade}

Há poucos dados empíricos sobre o papel das Reservas Extrativistas para a conservação da biodiversidade silvestre em geral, já que a literatura biológica conservacionista enfatiza mamíferos vertebrados, sem incluir indicadores de biodiversidade de invertebrados, répteis ou aves.

Há sobre esses grupos - anfíbios, insetos e aves - dados empíricos sobre um território habitado por seringueiros de 1895 a 1995, isto é, o rio Tejo. Esse território foi ocupado sem interrupção por seringueiros ao longo desse período, mesmo durante os momentos de colapso do mercado para a borracha (Barbosa de Almeida, 1993).

Um esforço intensivo de pesquisa (1994-1995) no rio Tejo - parte da Reserva Extrativista do Alto Juruá a partir de 1990 -, coordenado por Keith S. Brown Jr., dedicou-se ao estudo de borboletas, anfíbios, pássaros e insetos como indicadores de biodiversidade, com financiamento da Fundação McArthur e do IBAMA, e pesquisa da Universidade de São Paulo, da Universidade Estadual de Campinas (borboletas e anfíbios), da Universidade Federal do Acre (vegetais) e do Museu Goeldi (pássaros).

Os resultados indicaram biodiversidade máxima para todos os grupos estudados. Para borboletas, foram encontradas 1.620 espécies com 1.302 horas de pesquisa no rio Tejo (c. 300.000 ha, $60 \%$ da área da Reserva), índice inferior apenas ao de Cacaulândia, com 1.730 espécies por 5.000 horas de esforço de pesquisa de Keith Brown Jr. da Universidade Estadual de Campinas (Brown Jr. e Freitas, 2002: 33-42; Raimundo et al., 2003). Moisés Barbosa de Souza, da Universidade Federal do Acre e Adão Cardoso, da Universidade Estadual de Campinas, identificaram 113 espécies de anfíbios pertencentes a 32 gêneros e 15 famílias na Reserva Extrativista do Alto Juruá (Barbosa de Souza e Cardoso, 2002: 101-103), número ampliado para 126 espécies em 314 dias de observação em 50 pontos diferentes na Reserva Extrativista e no Parque Nacional da Serra do Divisor por Moisés Barbosa de Souza, onde diferenças de altitude criam novos nichos: "Em nenhuma parte do mundo é conhecida uma fauna de anfíbios que se equipare" (Barbosa de Souza, 2005, p. 16 ss.). Para pássaros, foram identificadas 543 espécies (Whitaker et al., 2002). Quanto à diversidade de espécies vegetais arbóreas, foram encontrados na Reserva Extrativista do Alto Juruá 507 indivíduos e 176 espécies apenas no Seringal Restauração que corresponde a 6\% do território da Reserva (Silveira et al., 2002, p. 65-75).

O esforço de pesquisa na Reserva Extrativista do Alto Juruá, em poucos anos (1994 -1995) nas cabeceiras do rio Tejo e com cerca de 30.000 hectares (sobre 503.000 hectares da Reserva como um todo), é muito inferior ao esforço de pesquisa dedicado ao longo de décadas na vizinhança de Manaus (Reserva Florestal Adolf Ducke) em área de 10.000 hectares ao longo de várias décadas. Não obstante, os índices de biodiversidade são da mesma ordem de grandeza. Há também dados sobre a biodiversidade agrícola na Reserva Extrativista do Alto Juruá que corroboram o papel de seringueiros-agricultores tradicionais como agentes de conservação e incremento da diversidade (Emperaire \& Almeida, 2012; Barbosa de Almeida et al., 2016). 


\section{Outras objeções}

\subsection{Bem-estar de famílias}

Freitas et al. afirmam que Reservas Extrativistas "foram criadas para conservação de ecossistemas e não para melhoria de vida de milhares de famílias" (Freitas et al., 2018, ênfase minha). Na verdade, como foi visto acima, "Reservas Extrativistas" é um conceito criado por seringueiros e não por ambientalistas, com o fim de assegurar direitos territoriais e bem-estar de famílias extrativistas com a salvaguarda dos recursos naturais que servem de base a esse bem-estar. De fato, o artigo 18 do decreto que cria o Sistema Nacional de Unidades de Conservação (SNUC) diz que a Reserva Extrativista "tem como objetivos básicos proteger os meios de vida e a cultura dessas populações, e assegurar o uso sustentável dos recursos naturais da unidade" (Brasil, 2000).

\subsection{Efeitos da ação racional e ação cooperativa}

O economista Alfredo K. O. Homma criticou desde cedo a proposta de Reservas Extrativistas argumentando que agentes econômicos, agindo racionalmente face a estímulos do mercado, inevitavelmente destruiriam recursos naturais - isto é, espécies exploradas pelo extrativismo - em uma conjuntura de preços declinantes, visando manter sua renda (Homma, 1989).

Essa argumentação se baseia na premissa de que camponeses florestais agem como o Homo Economicus de manuais de economia, ou melhor, como empresários que tomam decisões com base no critério da maximização individual de lucro ou de satisfação, sem cooperação e sem comunicação (essas são as suposições do chamado equilíbrio de Nash). De fato, é sob essa premissa que o regime de mercado conduz à destruição de recursos naturais. Sob essa suposição, Colin Clark demonstrou que, se a taxa de juros sobre o capital for maior do que o retorno monetário anual da exploração comercial de baleias a preços de mercado, a decisão racional de cada empresa baleeira será matar todas as baleias e convertê-las em capital (Clark, 1973). A suposição implícita nessa lógica sombria é a "impossibilidade de coalizões, comunicação e pagamentos laterais “ isto é, a ausência de cooperação, axioma introduzido por John Nash para obter uma solução para “jogos de $n$ pessoas" (Nash, 1950).

Mas se esse axioma é rejeitado, e se admitimos como possível a comunicação e cooperação entre os membros da coletividade, as conclusões não se mantêm. E de fato, a evidência empírica é que comunicação e cooperação regulam eficientemente o acesso coletivo a bens compartilhados em comum. Um exemplo é a regulamentação cooperativa da extração do xarope de maple no Canadá. Em vez de "aniquilamento de recursos", o regime de cooperativa mantém o nível de preços estável regulando a oferta, controlando a qualidade e preconizando técnicas sustentáveis de exploração. Não há nada de inexorável na suposta "lei do aniquilamento de recursos extrativos" formulada por Homma.

Para um exemplo mais familiar, segundo o Instituto da Amazônia, citando técnico da Empresa Brasileira de Pesquisa Agropecuária - Embrapa/ Acre, a expansão da produção de castanha no Estado a partir de 2005, mantendo-se como segundo produtor até 2011, deveu-se à criação de uma cooperativa 
e a políticas que estimularam a industrialização no estado (Instituto Amazônia, 2018).

A previsão da "tragédia dos recursos em comum" baseia-se na confusão entre "recursos de livres acesso" (sem dono) e "recursos coletivamente explorados" sob regras de uso compartilhadas (McCay \& Acheson, 1987; Gibson et al., 2000; Bromley, 1991). Essa previsão ignora também o fato de que sistemas tradicionais de regras de uso de recursos possam evoluir para instituições cooperativas modernas (Ostrom 1990; 1993).

De fato, Reservas Extrativistas são uma resposta à "tragédia dos recursos comuns". Em 1986, durante o famoso "empate da Bordon" - ação coletiva em que seringueiros de Xapuri buscaram bloquear o desmatamento de um seringal adquirido pela empresa -, Chico Mendes e outros líderes sindicais visitaram localidades cujos ocupantes haviam vendido suas posses e depois reocupado territórios da floresta. Os sindicalistas afirmavam então que a única maneira de evitar esse processo seria impossibilitar o desmembramento e a venda dos seringais, na forma de propriedade da União com usufruto dos moradores tradicionais (Barbosa de Almeida, 1993, Conclusão).

O agrônomo e economista Alfredo Homma afirma que "o extrativismo é um conceito romântico e apaixonado de alguns cientistas e ambientalistas", que supostamente "sonham aliar preservação e conservação de recursos ambientais com práticas extrativistas de pescadores, caçadores e coletores em florestas amazônicas" (Freitas et al., 2018), desprezando o fato de que o termo e o conceito foram formulados por sindicalistas amazônicos. Mas cabe lembrar que, em contraposição ao "romantismo" de pesquisadores que defendem a viabilidade de sistemas tradicionais de uso de recursos, há o "pragmatismo" que consiste em dedicar o foco da pesquisa para a geração de tecnologias que visam aumentar a produtividade de empresas exportadores de grãos - com atenção marginal a pequenos produtores e a cultivadores indígenas e aos biomas em que vivem (Santonieri, 2015).

\subsection{Falência preditiva do modelo de evolução tecnológica de Homma}

Como observação final, consideremos agora as previsões catastróficas do modelo microeconômico proposto originalmente por Homma para o extrativismo. Homma previa no início da década de 1993, no momento em que o programa de Reservas Extrativistas ganhava atração, a seguinte sequência como lei inexorável: (1) o produtivo extrativo será substituído por produtos domesticados ou sintéticos à medida que a demanda aumentar e os preços subirem, em virtude da rigidez da oferta, que é limitada pela disponibilidade natural de vegetais com baixa densidade; (2) em consequência da queda de preços, os extrativistas aniquilarão os recursos naturais visando compensar suas perdas com a extração em escala insustentável (Homma 1993).

Quanto ao ponto (1), eis o que diz o próprio Alfredo Homma em entrevista de 2016:

É interessante verificar que o desaparecimento da pro-
dução extrativa de castanha-do-pará na Amazônia não
decorreu de sua substituição pela produção proveniente
de plantios, como tem ocorrido para a maioria das 3 mil
plantas que foram domesticadas nestes últimos 10 mil
anos. No caso da população de castanheiras no sudeste
paraense, as razões da desintegração da economia ex-
trativa estão relacionadas com o conflito decorrente da
ocupação comum do espaço geográfico (...) A destruição
dos estoques de castanhais constitui efeito colateral de
problemas econômicos e sociais locais e de fora da região
(Homma, 2016). 
Em que pese a elevação dos preços da castanha-do-pará e o aumento do consumo nacional, e apesar do pesado subsídio tecnológico oferecido pela pesquisa de castanheiras cultivadas oferecido pela Embrapa, não houve substituição do extrativismo pelo "plantio racional". Em vez disso, o "aniquilamento" de castanhais resultou do desmatamento, e não da sobre-exploração de castanhais nativos. Assim, no Brasil a fonte principal da castanha do Pará são ainda os castanhais silvestres, apesar da existência de tecnologia desenvolvida pela Embrapa para o cultivo da castanheira. Castanhais nativos continuam após décadas de exploração desde o diagnóstico de Homma em 1993 como componentes importantes da economia florestal de extrativistas nos estados do Acre, no Amazonas e no Pará. Enquanto isso, a Bolívia tornou-se o principal exportador mundial do produto, com base em castanhais silvestres e na organização cooperativa. Não é preciso dizer mais sobre as previsões do modelo de "aniquilamento de recursos naturais" em consequência da ampliação do mercado.

Quanto ao ponto (2), seringais nativos de Hevea brasiliensis não foram aniquilados nem deixaram de produzir borracha no Acre ao longo de todo o século XX, apesar do crescimento mais que exponencial da oferta de borracha cultivada na Índia e no Sudeste Asiático entre 1912 e 1920 e da brutal queda de preços resultante, que perdurou até 1943. A atividade extrativista no Território do Acre não foi interrompida de 1912 e até 1943, embora com redução no volume de produção, nem houve destruição das seringueiras nesse período, embora não tenha havido subsídio algum no período (Barbosa de Almeida, 1993). Como não houve aniquilação de recursos durante essas três décadas de depressão, foi possível a retomada da atividade a partir de 1943, com preços garantidos pelos EUA e pelo governo brasileiro. As previsões otimistas de substituição da borracha natural por equivalentes sintéticos tampouco se materializaram, e a borracha natural ainda é insubstituível em aplicações como luvas cirúrgicas, pneumáticos, preservativos, isolamento de vidros e de componentes de foguetes espaciais. Seringueiros no Acre e no Xingu produzem borracha nativa como insumo para sola de sapatos e borracha de apagar, conforme pode-se observar diretamente.

Seringueiros e ribeirinhos não são empresas exportadoras, e sim economias camponesas de base familiar com múltiplos usos da floresta. Os modelos de plantação intensiva de seringueiras desenvolvidos pela Embrapa (com tecnologia baseada em agrotóxicos, estimulantes e clones importados) fracassaram na Amazônia durante as diferentes fases do PROBOR, embora seringueiros e alguns seringalistas tivessem êxito com plantios semiextensivos, utilizando variedades locais e permitindo a vegetação nativa, conforme verifiquei em diferentes localidades (Barbosa de Almeida, 2012a).

Homma caracterizou tecnologias extrativistas como um "carro velho" - em oposição a bicicletas que antecederam o "carro". Seguindo essa analogia a pesca oceânica ou fluvial seria "carro velho" em relação à produção de peixes em tanques alimentados por ração e antibióticos. Contudo, peixes produzidos com tais tecnologias são produtos inferiores do ponto de vista de consumidores de elite, que estão dispostos a pagar mais por peixes de mar aberto e de rios, assim como há mercados para carros vintage - "carro velho".

Há uma argumentação mais forte, a de que agricultores indígenas e camponeses domesticaram no Neolítico (c. 10.000 - 7.000 A.C.) em diferentes continentes todas as espécies vegetais e animais 
que formam hoje a base da alimentação mundial usando a tecnologia de "carro velho", que consiste em gerar novas variedades agrícolas a partir da experimentação e da seleção artificial (cf. Darwin, 1868; Nabhan, 2009). Comunidades indígenas e camponesas continuam a produzir novas variedades agrícolas em sistemas agrícolas onde a agricultura e a coleta são entrelaçadas (Emperaire \& Peroni, 2007; Emperaire et al., 2010). Os resultados dessas técnicas de "carro velho" são sistematicamente armazenados em câmeras frias da Embrapa-Cenargen (Santonieri, 2017). De resto, a bicicleta nunca foi substituída pelo "carro novo" de Henry Ford (Manuel Ruiz-Pérez, comunicação pessoal).

\subsection{Produtividade baixa ou altíssima produtividade?}

Alfredo Homma apontou para a baixa produtividade nas Reservas Extrativistas (Homma 1989, p. 184, passim), sem especificar o indicador de produtividade empregado. Pode-se inferir que o indicador subentendido por Homma é a produtividade física (quilos ou toneladas de produto por ano por hectare), que depende de condições naturais, da tecnologia (e.g. grande escala, homogeneidade do produto, maquinaria), do tamanho do mercado e do nível de preços (havendo ainda o papel de subsídios governamentais).

Isso significa que o retorno da atividade - seja extrativa, seja agrícola - flutuará segundo variações do mercado nacional e internacional que fogem inteiramente ao controle de uma família florestal - ao passo que o retorno da agricultura e da coleta de produtos alimentares não será afetada por essas variações. Uma empresa poderá realocar seus fatores seguindo as flutuações de mercado; mas a estratégia segura para uma família será assegurar o alimento para seus membros. O que parece irracional para o empresário é a estratégia segura para o chefe de família.

Consideremos um exemplo de como diferentes indicadores de produtividade levam a avaliações opostas sobre o uso de florestas tropicais: na Reserva Extrativista do Alto Juruá, cerca de 900 famílias residiam em 1990 em um território de $5.061 \mathrm{~km}^{2} \mathrm{~m}$ com uma área média de cerca de 550 ha por família. A área efetivamente explorada por família (território ocupado por estradas de seringa declaradas em levantamento de 1990) foi estimada conservadoramente em 300 hectares, o que corresponde aproximadamente a cerca de 300 a 400 seringueiras, distribuídas em duas a três estradas de seringa (Barbosa de Almeida et al., 2016, Barbosa de Almeida, 1993; Emperaire \& Barbosa de Almeida, 2002).

Nas zonas de alta produtividade, como o rio Bagé ou o Riozinho da Restauração, seringueiros obtinham 10 a 12 quilos de borracha (após defumação do látex líquido) por dia de trabalho, na mesma ordem de grandeza da produtividade por trabalhador de seringais de cultivo. Consideremos agora a produtividade por área. Seringais de cultivo comportam, conforme o espaçamento escolhido, 400 seringueiras por hectare, enquanto os seringais silvestres do alto Juruá apresentavam em média uma seringueira por hectare. Isso significa que seringais de cultivo são 400 vezes mais produtivos do que seringais nativos, quando a produtividade é medida como produto (quilos de borracha) por hectare.

Por outro lado, um hectare de floresta no alto rio Tejo comporta 500 árvores por hectare (sem contar arbustos e cipós), com 176 espécies por hec- 
tare (Daly \& Silveira, 2002; Silveira et al., 2002), contra uma espécie ou duas por hectare de seringal cultivado (e.g. seringueiras e cacau). Sob esse ponto de vista, o seringal florestal é de 100 a 200 vezes mais produtivo do que o seringal de cultivo quando a produtividade é medida como biodiversidade por hectare.

Mary Allegretti argumentou que uma família de seringueiros protege 400 hectares de floresta (Allegretti, 1990; 2008), prestando um serviço ambiental significativo. De um lado há a maximização do valor de mercado com minimização de variedade natural e social; de outro, a maximização da diversidade ecológica e social.

\section{Aportes positivos das Reservas Extrativistas}

Passamos a listar contribuições conceituais e práticas do programa de Reservas Extrativistas.

\subsection{Direitos territoriais e direitos sociais}

A Reserva Extrativista é a reforma agrária dos seringueiros. É o reconhecimento de áreas de floresta, ocupadas tradicionalmente por seringueiros e outros extrativistas, como áreas de domínio da União, com usufruto exclusivo dos seringueiros organizados em cooperativas ou associações. Nas Reservas Extrativistas, não há títulos individuais de propriedade. Nelas serão respeitadas a cultura e as formas tradicionais de organização e de trabalho dos seringueiros, que continuarão a realizar a extração de produtos de valor comercial como a borracha, a castanha e muitos outros, bem como a caça e a pesca não predatórias, juntamente com pequenos roçados de subsistência em harmonia com a regeneração da mata. As Reservas Extrativistas não serão áreas inviáveis economicamente: garantida a floresta, os seringueiros organizados aumentarão a produtividade, introduzindo inovações tecnológicas adequadas. Além disso, darão continuidade à criação de escolas, postos de saúde e cooperativas geridas por seringueiros. A Reserva Extrativista não é apenas a reforma agrária dos seringueiros, mas também uma forma de preservação da natureza pelos que dela dependem, e uma alternativa econômica para a Amazônia (STR/CNS/CUT 1989, p. 16).

O programa de Reservas Extrativistas significa o reconhecimento de direitos territoriais de ocupantes de territórios tradicionais. Esse reconhecimento estende a seringueiros, castanheiros, ribeirinhos, pescadores artesanais e outros residentes que utilizam tradicionalmente e com baixo impacto territórios como florestas, chapadas e veredas, faxinais, praias e mangues direitos que a legislação não reconhecia. As Reservas Extrativistas são, assim, instrumentos de justiça e de inclusão social para povos e comunidades detentoras de ricas tradições culturais de habitantes de florestas amazônicas (seringueiros, castanheiros, coletores de açaí), de chapadas e veredas (sertanejos) e de outros ambientes de alta biodiversidade e baixa demografia: ribeirinhos, pescadores artesanais, faxinalenses e outros mais que habitam florestas, barrancos de rio, praias e costões, chapadas e veredas (Barbosa de Almeida, 1995; Benatti 1998; 2003; Almeida A. B. W., 2004; Almeida A. B. W.; 2006; Torres, 2017). Foi o movimento dos seringueiros amazônicos que trouxe pela primeira vez esses "povos invisíveis" à luz. De fato, raríssimas publicações (Allegretti, 1979; Parker, 1985) mencionam seringueiros como habitantes da Amazônia contemporânea. Desde então, cresceu o número de publicações sobre povos "invisíveis" da Amazônia (Nugent, 1993; Adams et al., 2006; Pinsard Vianna, 2008), sob denominações como sociedades caboclas, seringueiros e castanheiros, ribeirinhos e caiçaras, faxinalenses e povos de fundo de pasto. 


\subsection{Proteção de terras públicas contra a grilagem e o uso predatório}

[Nas Reservas Extrativistas] serão respeitadas a cultura e as formas tradicionais de organização e de trabalho dos seringueiros, que continuarão a realizar a extração de produtos de valor comercial como a borracha, a castanha e muitos outros, bem como a caça e a pesca não predatórias, juntamente com pequenos roçados de subsistência em harmonia com a regeneração da mata. (Plataforma do Conselho Nacional do Seringueiros, em STR Xapuri, CNS e CUT, 1989).

A expulsão de moradores tradicionais por grileiros, fazendeiros, madeireiros e outros agentes ocorreu no Acre nas décadas de 1970 e de 1980 e continua a ocorrer na Terra do Meio, bacia do rio Xingu, nas primeiras décadas do século XXI. Com a criação de Reservas Extrativistas, terras públicas escaparam da expropriação por grileiros, representando significativa proteção destas terras que, ao invés de serem apropriadas pelo agronegócio e pela exploração madeireira, permanecem no domínio público com usufruto de comunidades tradicionais sujeitas a regras de conservação. Essa é sem dúvida uma das razões para a oposição às Reservas Extrativistas e modelos análogos delas derivados: a disputa pela apropriação de terras públicas (Almeida A.W.B., 2004; 2012). Essa disputa opõe, de um lado, interesses privados - empresas imobiliárias, fazendeiros, agropecuaristas grileiros que fazem a tarefa de expulsar, de outro, moradores tradicionais e legitimar legalmente o esbulho fundiário. No fundo dessa disputa, está o conflito entre a apropriação privada de patrimônios públicos, e regimes comunitários de uso durável de bens públicos (Torres et al., 2017). As terras em disputa são áreas antes não interessantes economicamente que se tornaram alvo de especuladores e do agronegócio após a abertura de estradas e do fornecimento de energia por usinas hidrelétricas. A ocupação tradicional por comunidades de seringueiros, castanheiros, pescadores artesanais, coletores de babaçu, sertanejos, faxinalenses constitui uma barreira contra a apropriação dessas terras públicas e contra a expropriação de seus antigos ocupantes pela grilagem e pelo agronegócio.

\subsection{Uso compartilhado de recursos naturais}

Reforma Agrária. 1. Desapropriação dos seringais nativos. 2. Que as colocações ocupadas pelos seringueiros sejam marcadas pelos próprios seringueiros conforme estradas de seringa. 3. Não divisão das terras em lotes. 4. Definição das áreas ocupadas por seringueiros como Reservas Extrativistas, assegurado seu uso pelos seringueiros. 5. Que não haja indenização das áreas desapropriadas, não recaindo seu custo sobre os seringueiros. 6. Que sejam respeitadas as decisões do $4^{\circ}$ Congresso Nacional dos Trabalhadores Rurais, no que diz respeito a um modelo específico de reforma agrária para a Amazônia que garanta um mínimo de 300 ha e um máximo de 500 ha por colocação, obedecendo à realidade extrativista da região. 7. Que os seringueiros tenham assegurado o direito de enviar seus delegados à Assembleia Nacional Constituinte para defender uma legislação florestal e fundiária de acordo com suas necessidades específicas. Da Plataforma do Conselho Nacional dos Seringueiros, lida por Chico Mendes no I Encontro Nacional do Seringueiros, em Brasília, em 17 de outubro de 1985 (em STR/CNS/CUT, 1989, p. 22).

As Reservas Extrativistas inovaram ao reconhecerem a posse coletiva de territórios de uso compartilhado, em regime de usufruto (Benatti, 2011). Tais regimes de uso têm sido extensamente tratados como alternativas viáveis para a gestão de recursos coletivamente apropriados (Ostrom, 1990). No conceito original, Planos de Uso elaborados por comunidades e a gestão compartilhada entre Associações e o Estado deveriam orientar o governo nas Reservas com responsabilidades atribuídas a mora- 
dores e convênios com outras instituições (Brasil, 1990). Planos de uso incluem limites máximos para manejo agrícola, regras de extração sustentáveis e disposições sobre caça e pesca, além de regras de entrada e saída e outras disposições (Ruiz-Pérez et al. 2005, p. 221). Há extensa literatura internacional que reconhece regimes de uso coletivo ou comunal de recursos como alternativas eficientes ao regime de propriedade privada e ao regime de controle e comando estatal, exemplificada por artigo publicado em Science com exemplo de Reserva Extrativista (Dietz et al., 2003a; 2003b) com o caso brasileiro.

Na Reserva Extrativista do Alto Juruá, ao longo da década de 1990 vários convênios tanto com o IBAMA como com universidades e outras instituições, sustentaram a auto-gestão do território pela Associação de Seringueiros e Agricultores, para cooperativismo, saúde, educação e fiscalização, com fiscais moradores credenciados pelo IBAMA para registrar invasões e violações às regras (sobre a implementação das regras e resolução de conflitos, ver Barbosa de Almeida \& Pantoja, 2004). Essa afirmação corrobora noção de que é possível uma "evolução institucional" de regras tradicionais para o governo de territórios coletivamente ocupados (Ostrom et al., 1993, p. 319-329).

\subsection{Serviços ambientais e conhecimentos tradicionais}

As Reservas Extrativistas valorizam sistemas tradicionais de uso múltiplo de territórios ricos em recursos naturais, e conhecimentos a eles associados, antecipando a tendência de valorizar a coprodução de conhecimento com colaboração de moradores e de pesquisadores acadêmicos (Klenk et al., 2015; Peters, 2018). Reservas Extrativistas, combinando baixa densidade demográfica com técnicas de baixo e baixíssimo impacto, prestam relevantes serviços sociais e ambientais, que incluem a conservação da cobertura florestal e da diversidade vegetal e animal, e conservação da diversidade agrícola (Fearnside, 1989; 1992; Allegretti, 1990).

Há estudos sobre a eficácia das áreas protegidas para a conservação (Soares-Filho et al., 2006) que indicam que áreas protegidas com presença humana e protagonismo local de gestão apresentam melhores resultados na conservação e na regeneração de áreas florestais desmatadas e degradadas (Oldekop et al., 2016). Reservas Extrativistas também mostram resultados melhores do que outras modalidades de reforma agrária para povos tradicionais (Ruiz-Perez et al., 2005).

\subsection{Ciência da Floresta}

Há uma ciência conceitual - formulada por intelectuais que se utilizam de modelos históricos, analógicos e matemáticos, submetidos ao crivo da experimentação controlada e da evidência histórica e estatística, e há conceitos que se atualizam em práticas e atividades resultantes da interação entre percepções e experiência cotidiana articulados por visões de mundo. Essa distinção tem sido corroborada pela literatura que trata do papel de conhecimentos tradicionais e de sistemas tradicionais de uso da natureza - remontando a Darwin. Reservas Extrativistas são um exemplo de resultado da sabedoria de moradores da floresta, porque não surgiu de planejadores, mas de um encontro em que se revelaram, de um lado, enciclopédicos co- 
nhecimentos da floresta tropical, e, der outro lado, uma compreensão inédita de sistemas sociais de uso da terra, com base em décadas de experiência no interior da floresta e na interface com o sistema nacional e mundial (Carneiro da Cunha \& Barbosa de Almeida, 2000).

\subsection{Entraves}

As Reservas Extrativistas, que fazem parte do Sistema Nacional de Unidades de Conservação, são hoje constrangidas por regras desse sistema e do ICMBio. Essas regras retiram a autoridade e a legitimidade das coletividades locais, porque dão autoridade absoluta a "chefes" - jovens biólogos sem experiência e nomeados sem consulta aos moradores, e que após alguns anos abandonarão o cargo. Outro fator que afeta as Reservas Extrativistas federais é a ausência de recursos para implementar programas de educação, saúde e desenvolvimento econômico. Um entrave importante enfrentado hoje pelos moradores tradicionais das Reservas Extrativistas é a usurpação dos direitos ao autogoverno e de cidadania de seus moradores tradicionais no interior do ICMBio, em flagrante desacordo com o espírito das Reservas Extrativistas tal como foram propostas por Chico Mendes (Barbosa de Almeida $\&$ Rezende, 2017). O atentado ao direito de auto-gestão nas Reservas Extrativistas e RDS é, a meu ver, o principal retrocesso imposto à visão de Chico Mendes, juntamente com a imposição de exploração de madeira. $\mathrm{O}$ autoritarismo burocrático do ICMBio sobre as Reservas Extrativistas começa com a instituição, pelo SNUC, de "Conselhos Deliberativos" como instância de gestão das Reservas Extrativistas e das Reservas de Desenvolvimento Sustentável.
Aparentemente democrática, essa forma de gestão retira das Associações e Cooperativas o papel de representantes dos moradores, atribuindo a tomada de decisões a um conselho misto onde os moradores comparecem como indivíduos juntamente com representantes do município. Os Conselhos dificilmente podem atuar de verdade como órgão de gestão, dada a dificuldade de reuniões para uma população dispersa na floresta, e de fato, a autoridade está nas mãos de seu presidente que é nomeado pelo ICMBio. Esse modelo é único, já que as demais unidades de conservação podem ser administradas por convênios entre o ICMBio e Associações Civis, tendo os Conselhos papel consultivo e não deliberativo. A disposição está, aliás, em contradição direta com o decreto de que instituiu a Reserva Extrativista do Alto Juruá (Decreto 59.963 de 23 de janeiro de 1990), que preconiza a administração da Reserva por convênio entre Associações e o poder público.

Outro episódio que marca a destruição de mecanismos de auto-gestão nas Reservas foi a extinção silenciosa do CNPT - Centro Nacional de Desenvolvimento Sustentado das Populações Tradicionais -, órgão inicialmente subordinado diretamente à presidência do IBAMA e que administrava políticas especiais para as Reservas Extrativas com presença de representantes nacionais dos seringueiros. Esse organismo foi substituído pela "transversalização" da administração das unidades de conservação, o que, em outras palavras, significa que Reservas Extrativistas passaram a ser tratadas no mesmo plano que todas as demais unidades de conservação, obliterando-se assim qualquer distinção de fundo entre as Reservas Extrativistas e as demais Unidades de Conservação. Após trinta anos do assassinato de Chico Mendes, eis os fatos: a extinção da cogestão entre associações locais e o Estado, com a institui- 
ção do "Conselho Deliberativo" com composição heteróclita, a extinção do CNPT e a desvalorização dos Planos de Uso em favor de Planos de Manejo elaborados por técnicos. Com essas mudanças, a proposta inicial de um modelo territorial baseado na posse coletiva e na auto-gestão foi substituída, sem consulta aos interessados, do campo semântico de "territórios de interesse social e ecológico" para o campo das "unidades de conservação", enquanto a autonomia para definição de parâmetros de bem viver pelos povos locais era cada vez mais submetida às novas formas de dominação associadas a conceitos como conservação e biodiversidade (Lobão 2006, p. 153 e 227; Souza Filho, 2015).

Essas mudanças levaram ao surgimento de uma série de restrições a atividades tradicionais sob a autocracia de chefes inexperientes formados como biólogos. Perdeu-se do horizonte, portanto, o reconhecimento dos direitos de comunidades locais sobre territórios tradicionalmente habitados, em desacordo com acordos internacionais dos quais o Brasil é signatário (OIT, 2011; MPF, 2014).

Esse processo não é irreversível, mas a recuperação do espírito original das Reservas Extrativistas dependerá da retomada do espírito combativo e de independência que marcou os primeiros anos do Conselho Nacional dos Seringueiros e de sua articulação com movimentos sociais na escala nacional, defendendo os direitos das populações tradicionais em seus territórios.

\section{Agradecimentos}

A Roberto Rezende e Juan Doblas Pietro.

\section{Referências}

Adams, C.; Murrieta, R.; Neves, W. (orgs.). Sociedades Caboclas Amazônicas: Modernidade e Invisibilidade. São Paulo: FAPESP e ANABLUME, 2006.

Alencar, A.; Pereira, C.; Castro, I.; Cardoso, A.; Souza, L.; Costa, R.; Bentes, A. J.; Stella, O;, Azevedo, A.; Gomes, J.; Novaes, R. Desmatamento nos Assentamentos da Amazônia. Histórico, Tendências e Oportunidades. Brasília: IPAM (Instituto de Pesquisa Ambiental da Amazônia), 2016.

Allegretti, M. Os Seringueiros. Estudo de Caso em um Seringal Nativo do Acre. Brasília, Tese (Dissertação de Mestrado em Antropologia Social) - Universidade de Brasília, 1979.

Allegretti, M. Alternatives do Deforestation: steps towards sustainable use of the Amazon rain forest. In: Anderson, A. B. (Org.). Alternatives to deforestation: steps towards sustainable use of the Amazon rain forest. New York: Columbia University Press, 1990, pp. 252-264

Allegretti, M. A construção social de políticas públicas: Chico Mendes e o movimento dos seringueiros. Desenvolvimento e Meio Ambiente, 18, 39-59, 2008.

Almeida, A. W. B. Terras Tradicionalmente Ocupadas: processos de territorialização e movimentos sociais. Revista Brasileira de Estudos Urbanos e Regionais, 6(1), 9-32, 2004. Disponível em: <http://www.anpur.org.br/ revista/ rbeur/index.php/rbeur/article/view/102/86>.

Almeida, A. W. B. Quilombolas, Quebradeiras de Coco Babaçu, Indígenas, Ciganos, Faxinalenses e Ribeirinhos: movimentos sociais e a nova tradição. Proposta, (29)107/108, 25-38, 2006.

Almeida, A. W. B. Territórios e territorialidades específica na Amazônia: entre a "proteção" e o "protecionismo". Caderno CRH, 25(64), 2012. doi: 10.1590/S010349792012000100005

Barbosa de Almeida, M. W. Rubber Tappers of the Upper Jurua River, Brazil: The Making of a Forest Peasantry. Cambridge, Tese (Ph.D. em Antropologia Social) - University of Cambridge, 1993.

Barbosa de Almeida, M. W. O Estatuto da Terra e as Re- 
servas Extrativistas. Reforma Agrária, 25, 153-168, 1995.

Barbosa de Almeida, M. W. Direitos à Floresta e Ambientalismo: os seringueiros e suas lutas. Revista Brasileira de Ciências Sociais, (19)55, 34-53, 2004a.

Barbosa de Almeida, M.; Pantoja, M. C. Justiça Local nas Reservas Extrativistas. Raizes, 23(01-02), 27-41, 2004b.

Barbosa de Almeida, M. W. As Colocações como Forma Social, Sistema Tecnológica e Unidade de Recursos Naturais. Terra Indígena, 7(54), 1990, pp. 29-39. Republicado com notas em Mediações, vol. 17, n.1, jan./jun. 2012, pp. 121-147.

Barbosa de Almeida, M. W. História Ambiental e História Social da Amazônia (I), História Ambiental e História Social da Amazônia (II): Alternativa de Cultivo por Seringueiros. In: Aquino, T. T. (Org.). Papo de Índio. Manaus, Universidade do Estado do Amazonas Edições (UEA), 2012a, pp. 262-267 e 270-273.

Barbosa de Almeida, M. W.; Rezende, R. S. Uma Nota sobre Comunidades Tradicionais e Unidades de Conservação. Ruris, 7(2), 185-, 2013.

Barbosa de Almeida, M. W.; Postigo, A. A.; Costa, E. M. L.; Ramos, R. M.; Ramos, R. F. e Barbosa de Melo, A. Usos Tradicionais da Floresta por Seringueiros na Reserva Extrativista do Alto Juruá. In: Siviero, A.; Ming, L.C.; Silveira, M.; Daly, D.; Wallace, R. (orgs.) Etnobotânica e Botânica Econômica do Acre. Rio Branco: Editora da Universidade Federal do Acre (Edufac), 2016, pp. 14-37.

Barbosa de Souza, M.; Cardoso, A. J. Anfíbios Registrados na Reserva Extrativista do Alto Juruá de Outubro de 1993 a Dezembro de 2000. In: Carneiro da Cunha, M.; Barbosa de Almeida, M. W. 2002, pp. 101-103.

Barbosa de Souza, M. Anfibios. Reserva Extrativista do Alto Juruá e Parque nacional da Serra do Divisor. Série Pesquisa e Monitoramento Participativo em Áreas de Conservação Gerenciadas por Populações Tradicionais, vol. 2. Rio Branco: Centro de Ciências Biológicas e da NaturezaUniversidade Federal do Acre; Cruzeiro do Sul: Associação dos Seringueiros e Agricultores da Reservas Extrativista do Alto Juruá (ASAREAJ); Campinas: Editora do Instituto de Filosofia e Ciências Humanas, 2005.
Benatti, J. H. Posse agroecológica: um estudo das concepções jurídicas dos apossamentos de camponeses agroextrativista na Amazônia. Revista América Indígena, 57, 375-395, 1998.

Benatti, J. H. Posse agroecológica e manejo florestal. Curitiba: Juruá, 2003.

Benatti, J. H. Propriedade comum na Amazônia: acesso e uso dos recursos naturais pelas populações tradicionais. In: Sauer, S. \& Almeida, W. (Orgs.). Terras e territórios na Amazônia: demandas, desafios e perspectivas. Brasília: Editora Universidade de Brasília, 2011, p. 93-113.

Brandon, K.; Redford, K. H.; Sanderson, S. (Orgs.). Parks in Peril: People, Politics, and Protected Areas. Washington: Island Press, 1988.

Brasil. Decreto 98.863 de 23 de janeiro de 1990. Cria a Reserva Extrativista do Alto Juruá. Brasília, 1990a.

Brasil. Decreto 98.897 de 30 de janeiro de 1990. Dispõe sobre as reservas extrativistas e dá outras providências. 1990b.

Brasil. Lei N. 9,.985 de 18 de julho de 2000. Institui o Sistema Nacional de Unidades de Conservação da Natureza. 2000 .

Brasil. Plano de Manejo da Reserva Extrativista Chico Mendes. Fonte: www.icmbio.gov.br/portal/images/stories/ imgs-unidades.../resex_chico_mendes.pdf. 2006. Acessado 2018-05-23.

Bromley, D. W. Environment and Economy. Property Rights \& Public Policy. Oxford: Blackwell, 1991.

Brown Jr., K. S.; Freitas, A. V. Diversidade Biológica no Alto Juruá: Avaliação, Causas e Manutenção. In: Carneiro da Cunha, M.; Barbosa de Almeida, M. W. Enciclopédia da Floresta, 2002, pp. 33-42.

Carneiro da Cunha, M.; Barbosa de Almeida, M. W. Indigenous People, Traditional People, and Conservation in the Amazon. Daedalus, Journal of the American Academy of Arts and Sciences, 129(2), 315-338, 2000.

Carneiro da Cunha, M. e Barbosa de Almeida, M. W. Enciclopédia da Floresta. O Alto Juruá: Práticas e Conhecimentos das Populações. São Paulo: Companhia das Letras, 2002. 
Clark, C. Profit Maximization and the Extinction of Animal Species. The Journal of Political Economy, 81(4), 950-961, 1973.

Conceição, M. G.; Barbosa de Almeida, M. W. Macacos e soins (primatas) no Rio Tejo (Reserva Extrativista do Alto Juruá). Projeto "Can Forest Dwellers Manage Conservation Areas?”, financiado pela Fundação McArthur. Manuscrito (incluindo tabelas quantitativas e história natural), 1995.

CONFREM - Comissão Nacional de Fortalecimento das Reservas Extrativistas e Povos Tradicionais Extrativistas Costeiros e Marinhos/CNS - Conselho Nacional das Populações Extrativistas/IEA - Instituto de Estudos Amazônicos. Interesses econômicos pressionam pela extinção da Resex Canavieiras. 2018.

Daly, D. C.; Silveira, M. Aspectos Florísticos da Bacia do Alto Juruá. História Botânica, Peculiaridades, Afinidades e Importância para a Conservação. In: Carneiro da Cunha; Barbosa de Almeida 2002, pp 53-63.

Darwin, C. The Variation of Animals and Plantas under Domestication. 1868.

Di Deus, E. A Dança das Facas: Trabalho e técnica em seringais paulistas. Tese (Doutorado em Ciências Sociais), Universidade de Brasilia, 2017.

Dietz, T.; Ostrom, E.; Stern, P. C. The Struggle to Govern the Commons. Science, 302(5652), 1907-1912, 2003 a.

Dietz, T.; Ostrom, E.; Stern, P. C. Online Supplement to The Struggle to Govern the Commons. Science, 302(5652), 1907-1912, 2003b pp. 1-15.

Eisenberg, J. F.; Redford, K. H. Mammals of the Neotropics. The Central Neotropics. Vol. 3. Ecuador, Peru, Bolivia, Brazil. Chicago: Chicago Univesity Press, 1999.

Emmons, L.; Feer, F. Neotropical Rainforest Mammals. A Field Guide. Chicago e Londres: Chicago University Press, 1990.

Emperaire L.; Peroni N. Traditional management of agrobiodiversity in Brazil: a case study of manioc. Human Ecology, 36(5), 761-768, 2007.

Emperaire, L.; Barbosa de Almeida, M. W. Seringueiros e Seringas. In: Carneiro da Cunha, M.; Barbosa de Almeida,
M. W. (Orgs.). Enciclopédia da Floresta. O Alto Juruá: Práticas e Conhecimentos das Populações, São Paulo: Companhia das Letras, 2002, pp. 285-309.

Emperaire, L.; Robert, P.; Santilli, J.; Eloy, L.; van Velthem, L.; Katz, E.; Lopez, C.; Laques, A.; Carneiro da Cunha, M.; Barbosa de Almeida, M. Diversité agricole e patrimoine dans le moyen Rio Negro (Amazonie brésilienne). Les Actes du BRG, 7. 139-153, 2008.

Emperaire, L.; Carneiro Da Cunha, M.; Katz, E.; Oliveira, A. G. de; Santilli, J.; Velthem, L H. Van. 2010. Dossiê de registro do sistema agrícola tradicional do Rio Negro. Brasília: ACIMRN / IPHAN / IRD / Unicamp-CNPq, 2010. 235 p. http://portal.iphan.gov.br/bcrE/pages/conUfBemE. jsf?uf $=\mathrm{AM}$

Emperaire, L.; Barbosa de Almeida, M. W. Villes et Diversité Agricole au Brésil: flux, réseaux et mobilités. Paris: PIRVE (Programme Interdisciplinaire de Recherche Ville et Environnment), 2012.

Emperaire, L.; Barbosa de Almeida, M. W. Le périurbain en Amazonie, une ressource pour l'agrobiodiversité? In: Barles, S.; Blanc, N. (Orgs.). Écologies Urbaines sur le Terrain, Paris: Economica, Anthropos, 2016, v. 1, p. 28-29.

Fearnside, P. Reservas Extrativistas: uma estratégia de uso sustentado. Ciência Hoje, (14)81, 14-18, 1992.

Fearnside, P. Extractive Reserves in Brazilian Amazonia. Bioscience, 39(6), 387-393, 1989.

Freitas, J. S.; Farias Filho, M. C.; Homma, A. K. O.; Mathis, A. Reservas Extrativistas sem Extrativismo: uma Tendência em Curso na Amazônia? Revista de Gestão Social e Ambiental, 2018. doi: 10.24857/rgsa.v12il.1388

Gibson, C.; McKean, M.; Ostrom, E. (Orgs.). People and Forests. Communities, Institutions, and Governance. Cambridge: MIT Press, 2000.

Hardin, G. The Tragedy of the Commons. Science, 162(3859), 1243-1248, 1968.

Homma, A. K. O. Reservas Extrativistas: uma opção de desenvolvimento viável para a Amazônia? Revista Pará Desenvolvimento, 25, 38-48, 1989.

Homma, A. K. O. Extrativismo Vegetal na Amazonia. Limi- 
tes e Oportunidades. Brasilia: EMBRAPA, 1993.

Homma, A. K. O. "Porque o Brasil deixou de ser o maior produtor mundial de castanha-do-Brasil. Entrevista, 22 de agosto de 2016. http://www.todafruta.com.br/por-que-o-brasil-deixou-de-ser-o-maior-produtor-mundial-de-castanha-do-brasil/

ICMBio. Análise do Desmatamento nas Unidades de Conservação Federais Loalizadas na Amazônia. 2012. www. icmbio.gov.br/portal/images/stories/.../avaliacaodesmatamentoucsicmbio.pdf (acessado em abril de 2018).

ICMBio. Cadastro Nacional de Unidades de Conservação. 2018. http://www.mma.gov.br/areas-protegidas/cadastro-nacional-de-ucs/consulta-por-uc (acesso em abril de 2018).

ICMBio. Painel Dinâmico de Informações. 2018. http:// qv.icmbio.gov.br/QvAJAXZfc/opendoc2.htm?documen$t=$ painel_corporativo_6476.qvw\&host=Local\&anonymou$s=$ true. 2014 (acesso em abril de 2018)

INCRA. http://www.incra.gov.br/assentamentoscriacao

Instituto Amazonia. https://www.institutoamazonia.org.br/ acre-amazonas-e-para-lideram-producao-da-castanha-do-brasil-no-pais/. Acessado em abril de 2018.

ISA (Instituto Socioambiental). Unidades de Conservação no Brasil. https://uc.socioambiental.org/uso-sustentavel/ reserva-extrativista. Acessado em 22 de abril de 2016.

Klenk, N. L.; Meechan, K.; Pinel, S. L.; Mendez, F.; Lima, P. T.; Kammen, D. M. Stakeholders in climate science: beyond lip service? Local knowledge coproduction must be rewarded. Science, 350, 6262, 743-744, 2015.

Lévi-Strauss, C. Compte-rendu: Manuela Carneiro da Cunha e Mauro Barbosa de Almeida, eds. Enciclopédia da floresta. O Alto Juruá - práticas e conhecimentos das populações. L'Homme, 167-169, 366-369, 2003.

Lobão, R. J. S. Cosmologias Políticas do Neocolonialismo: como uma Política Pública pode se transformar em uma Política do Ressentimento. Niteroi: Editora da Universidade Federal Fluminense (EDUFF), 2010.

McCay, B. J.; Acheson, J. M. The Question of the Commons. The Culture and Ecology of Communal Resources. Tucson: University of Arizona Press, 1987.
MPF (Ministério Público Federal). Territórios de Povos e Comunidades Tradicionais e as Unidades de Conservação de Proteção Integral. Alternativas para o Asseguramento de Direitos Socioambientais. Manual de Atuação, 1. M. L. Grabner (org.). Brasilia: MPF 6a Câmara, 2014.

Murphy, R. B.; Steward, J. H. Tappers and Trappers: Parallel Process in Acculturation. Economic Development and Cultural Change, 4(4), 335-355, 1956.

Nabhan, G. P. Where our Food Comes From. Retracing Nikolay Vavilov's Quest to End Famine. Washington: Islandpress, 2009.

Nash, J. Non-cooperative Games. Tese (University of Princeton), 1950.

Nasi, R; Taber, A. and Van Vliet, N. Empty Forests, Empty Stomachs? Bushmeat and Livelihoods in the Congo and Amazon Basins, International Forestry Review, 13(3), 355368, 2011. doi: $10.1505 / 146554811798293872$

Novaro, A. J.; Redford, K. H.; Bodmer, R. E. Effect of hunting in source-sink systems in the neotropics. Conservation Biology, 14(3), 713-721, 2000.

Nugent, S. Amazonian Caboclo Society. An Essay on Invisibility and Peasant Economy. Oxford: Berg, 1993.

OIT - Organização Internacional do Trabalho. Convenção n. 169 sobre povos indígenas e tribais. Brasilia: OIT, 2011.

Oldekop, J. A.; Holmes, G.; Harris, W. E.; Evans, K. L. A global assessment of the social and conservation outcomes of protected areas. Conservation Biology, 30(1), 133-141, 2016.

Ostrom, E. Governing the Commons: The Evolution of Institutions for Collective Action. Cambridge, UK: Cambridge University Press, 1990.

Ostrom, E.; Gardner, R.; Walker, J. Rules, Games, \& Common-Pool Resources. An Arbor: The University of Michigan Press, 1993.

Pantoja Franco, M. Cl.; Barbosa de Almeida, M. W.; Conceição, M. G.; Lima, E. C.; Aquino, T. V.; Iglesias, M. P.; Mendes, M. K. Botar Roçados. In Carneiro da Cunha, M. e Barbosa de Almeida, M. W. Enciclopédia da Floresta, 249-283, 2002. 
Parker, E. P. (Org.). The Amazon Caboclo: Historical and Contemporary Perspectives. Studies in Third World Societies, vol. 32, 1985,

Parry, L.; Peres, C. A. Evaluating the use of local ecological knowledge to monitor hunted tropical-forest wildlife over large spatial scales. Ecology and Society, 20(3), 15, 2015. doi: 10.5751/ES-07601-200315

Peres, C. A. Effects of Subsistence Hunting on Vertebrate Community Structure in Amazonian Forests. Conservation Biology, 14(1), 240-253, 2000.

Peres, C. A.; Emilio, T.; Schietti, J.; Desmoulière, J. M.; Levi, T. Dispersal limitation induces long -term biomass collapse in overhunted Amazonian forests. www.pnas.org/ cgi/doi/10.1073/pnas.1516525113, 2015.

Peters, C. M. Managing the Wild. Stories of People and Plants and Tropical Forests. New Haven, Yale University Press, 2018.

Pinsard Vianna, L. De Invisiveis a Protagonistas. Populações Tradicionais e Unidades de Conservação. São Paulo: FAPESP e ANABLUME, 2008.

PRODES http://www.obt.inpe.br/OBT/assuntos/programas/ amazonia/prodes. Consultado em 20.08.18.

Raimundo, R. L. G.; Freitas, A. V. L.; Costa, R. N. S.; Oliveira, J. B. F.; Lima, A. F., Barbosa de Melo, A., Brown Jr.K. S. Manual de Monitoramento Ambiental usando Borboletas e Libélulas. Campinas: Instituto de Biologia (IB) e Instituto de Filosofia e Ciências Humanas (IFCH), 2003.

Ramos, R. M. Estratégia de caça e uso de fauna na Reserva Extrativista do Alto Juruá-AC. Tese (Dissertação de Mestrado em Ecologia) - Universidade de São Paulo - PROCAM, 2005.

Redford, K. H. The Empty Forest. BioScience, 42(6), 412422, 1992.

Robinson, J. G.; Redford, K. H. (Orgs.). Neotropical Wildlife Use and Conservation. Chicago e Londres: The University of Chicago Press, 1991.

Ruiz-Pérez, M. et al. Conservation and development in Amazonian extractive reserves: the case of Alto Juruá. Ambio: A Journal of the Human Environment, 34(3), 218-223, 2005.
Santonieri, L. R. Agrobiodiversidade e Conservação ex situ: reflexões sobre conceitos e práticas a partir do caso da Embrapa/Brasil. Tese de Doutorado (Universidade Estadual de Campinas), 2015.

Shepard, G. H Jr.; Levi, T.; Neves, E. G.; Peres, C. A.; Yu, D. Hunting in Ancient and Modern Amazonia: Rethinking Sustainability. American Anthropologist, 114(4), 652-667, 2012. doi: 10.1111/j.1548-1433.2012.01514.x

Silveira, M.; Torrezan, J. M. D. e Daly, D. Vegetação e Diversidade Arbórea da Região do Alto Juruá. In: Carneiro da Cunha, M.; Barbosa de Almeida, M. (Orgs.). Enciclopédia da Floresta, São Paulo, Companhia das Letras, 2002, pp. 65-75.

Soares-Filho, B. S.; Nepstad, D. C.; Curran, L.; Cerqueira, G. C.; Garcia, R. A.; Ramos, C. A.; Voll, E.; McDonald, A.; Lefebvre, P.; Schelesinger, P. Modelling Conservation in the Amazon Basin. Nature, 440, 520-523, 2006. doi: 10.1038/nature04389

Souza Filho, C. M. et al. (Orgs.). Direitos Territoriais de Povos e Comunidades Tradicionais em Situação de Conflitos Ambientais. Brasília: Instituto de Pesquisa Direitos e Movimentos Sociais - IPDMS), 2015.

STR/CNS/CUT. Chico Mendes. Coordenação Editorial: F. Pachalski, M. Allegretti, M. B. Pereira, M. W. B. de Almeida e N. Balcão. Xapuri e São Paulo: Sindicato dos Trabalhadores Rurais de Xapuri, Conselho Nacional dos Seringueiros e Central Única dos Trabalhadores, 1989.

Teixeira, C. $O$ aviamento e o barracão na sociedade do seringal. Dissertação de Mestrado, Universidade de São Paulo, 1980.

Torres, M.; Doblas, J.; Alarcon, D. F. Dono é Quem Desmata. São Paulo: Urutu-branco; Altamira: Instituto Agronômico da Amazônica, 2017.

Van Vliet, N.; Fa, J.; Nasi, R. Managing hunting under uncertainty: from one-off ecological indicators to resilience approaches in assessing the sustainability of bushmeat hunting. Ecology and Society, 2015.

Whitaker et al. Aves Registradas na Reserva Extrativista do Alto Juruá. In: Carneiro da Cunha, M.; Barbosa de Almeida, M.W. (Orgs.). Enciclopédia da Floresta, pp. 81-99, 2002. 
ANEXO 1 - Área, desmatamento até 2007 e desmatamento anual de 2008 a 2017 para 50 Reservas Extrativistas Federais segundo PRODES 2017 (em hectares).

\begin{tabular}{|c|c|c|c|c|c|c|c|c|c|c|c|c|c|}
\hline $\begin{array}{l}\text { Nome da } \\
\text { UC }\end{array}$ & Área da UC & $\begin{array}{c}\text { Area total } \\
\text { classes }\end{array}$ & $\begin{array}{l}\text { Desmat. } \\
\text { até } 2007\end{array}$ & $\begin{array}{l}\text { Desmat. } \\
2008\end{array}$ & $\begin{array}{c}\text { Desmat. } \\
2009\end{array}$ & $\begin{array}{c}\text { Desmat. } \\
2010\end{array}$ & $\begin{array}{c}\text { Desmat. } \\
2011\end{array}$ & $\begin{array}{c}\text { Desmat. } \\
2012\end{array}$ & $\begin{array}{c}\text { Desmat. } \\
2013\end{array}$ & $\begin{array}{c}\text { Desmat. } \\
2014\end{array}$ & $\begin{array}{l}\text { Desmat. } \\
2015\end{array}$ & $\begin{array}{c}\text { Desmat. } \\
2016\end{array}$ & $\begin{array}{c}\text { Desmat. } \\
2017\end{array}$ \\
\hline Totais & $12.429 .690,95$ & $11.770 .135,10$ & $332.356,79$ & $8.300,84$ & $5.300,25$ & $8.933,67$ & $4.875,81$ & $4.437,07$ & $3.734,49$ & $5.600,04$ & $7.836,65$ & $5.720,22$ & $4.139,32$ \\
\hline Alto Juruá & $530.356,83$ & $530.129,07$ & $10.867,86$ & 793,90 & & $1.948,06$ & 795,70 & 341,14 & 155,44 & 595,18 & 125,49 & 225,25 & 186,30 \\
\hline Arapixi & $133.185,01$ & $133.185,10$ & $2.475,60$ & 9,01 & 55,51 & 42,53 & 34,69 & 10,57 & 17,15 & 26,79 & 48,37 & 26,87 & 112,88 \\
\hline $\begin{array}{l}\text { Arióca- } \\
\text { Pruanã }\end{array}$ & $83.935,31$ & $83.940,07$ & $7.977,89$ & 137,72 & 112,40 & $1.132,37$ & 105,64 & 52,42 & 57,57 & 34,68 & 244,18 & 104,00 & 94,79 \\
\hline $\begin{array}{l}\text { Auatí- } \\
\text { Paraná }\end{array}$ & $144.761,29$ & $144.895,67$ & $1.521,24$ & 42,60 & 7,59 & 70,26 & 14,51 & & 6,80 & & 7,77 & & 8,00 \\
\hline $\begin{array}{l}\text { Barreiro das } \\
\text { Antas }\end{array}$ & $105.583,13$ & $105.583,15$ & 47,42 & 7,72 & & & & & & & & & \\
\hline $\begin{array}{l}\text { Chico } \\
\text { Mendes }\end{array}$ & $935.325,88$ & $935.215,63$ & $40.842,78$ & $1.155,29$ & 367,21 & 709,51 & $1.208,83$ & $1.261,34$ & $1.123,06$ & $2.224,30$ & $3.232,11$ & $3.390,83$ & $2.054,98$ \\
\hline $\begin{array}{l}\text { Chocoaré } \\
\text { - Mato } \\
\text { Grosso } \\
\end{array}$ & $2.949,08$ & $2.949,08$ & 261,77 & & & & & & & & & & \\
\hline $\begin{array}{l}\text { Baía do } \\
\text { Tubarão }\end{array}$ & $224.079,90$ & $6.706,87$ & 3,42 & & & & & & 1,38 & 2,29 & & & \\
\hline $\begin{array}{l}\text { Mata } \\
\text { Grande }\end{array}$ & $11.435,29$ & $11.435,29$ & $9.749,89$ & 194,84 & 174,51 & 86,85 & 77,63 & 84,28 & 7,57 & 28,58 & 37,41 & 8,53 & 10,54 \\
\hline $\begin{array}{l}\text { Arapiranga - } \\
\text { Tromaí }\end{array}$ & $186.108,90$ & $26.031,30$ & $2.112,90$ & & & & & 9,39 & & & & & \\
\hline Cururupu & $187.217,40$ & $43.565,95$ & $15.126,96$ & 19,67 & 0,21 & & & & & 2,97 & & & \\
\hline Itapetininga & $15.692,48$ & $15.692,46$ & $4.640,32$ & & 7,68 & & & & & & & & \\
\hline $\begin{array}{l}\text { São João da } \\
\text { Ponta }\end{array}$ & $3.400,19$ & $3.400,19$ & 137,62 & 9,37 & & & & & & 0,00 & 0,94 & 0,50 & \\
\hline $\begin{array}{l}\text { Alto } \\
\text { Tarauacá }\end{array}$ & $157.593,90$ & $157.593,89$ & $2.875,78$ & 311,02 & 65,00 & 326,81 & 232,37 & 185,54 & 22,75 & 174,65 & 88,09 & 41,27 & 16,52 \\
\hline Baixo Juruá & $180.463,74$ & $180.463,80$ & $2.563,54$ & 40,46 & 44,11 & 32,93 & 14,46 & & 10,09 & 81,82 & 21,57 & 19,37 & 17,06 \\
\hline $\begin{array}{l}\text { Cazumbá- } \\
\text { Iracema }\end{array}$ & $756.958,88$ & $756.965,68$ & $7.129,97$ & 92,87 & 86,78 & 284,96 & 282,44 & 199,72 & 193,69 & 155,16 & 205,31 & 270,87 & 178,60 \\
\hline Ciriaco & $8.129,85$ & $8.129,85$ & $5.539,53$ & 112,04 & 53,31 & & 15,76 & & & 22,37 & 6,76 & & \\
\hline
\end{tabular}




\begin{tabular}{|c|c|c|c|c|c|c|c|c|c|c|c|c|c|}
\hline $\begin{array}{l}\text { Extremo } \\
\text { Norte do } \\
\text { Tocantins }\end{array}$ & $9.110,46$ & $9.110,44$ & $8.487,93$ & 0,57 & & & & & & & & & \\
\hline $\begin{array}{l}\text { Lago do } \\
\text { Capanã } \\
\text { Grande }\end{array}$ & $305.696,51$ & $305.696,38$ & $2.967,19$ & 6,67 & 6,75 & 275,67 & & 34,72 & & & 32,30 & 6,41 & \\
\hline $\begin{array}{l}\text { Lago do } \\
\text { Cuniã }\end{array}$ & $50.688,44$ & $50.688,29$ & 223,89 & & & & & & & & & & \\
\hline Médio Juruá & $286.736,80$ & $286.736,79$ & $3.374,26$ & 42,16 & 28,13 & 42,96 & 10,07 & & 16,12 & 23,60 & 23,41 & 35,30 & 16,79 \\
\hline $\begin{array}{l}\text { Quilombo } \\
\text { Frechal }\end{array}$ & $8.785,64$ & $8.785,64$ & $8.785,64$ & & & & & & & & & & \\
\hline Rio Cajari & $504.880,00$ & $504.879,74$ & $3.082,97$ & 680,25 & 525,60 & 147,68 & 57,73 & 195,01 & 104,14 & 265,06 & 330,18 & 155,18 & 147,74 \\
\hline $\begin{array}{l}\text { Rio } \\
\text { Cautário }\end{array}$ & $74.294,94$ & $74.294,97$ & 483,31 & & & & & & 440,86 & & & & \\
\hline Rio Jutaí & $274.780,06$ & $274.780,06$ & $1.538,84$ & 107,83 & 60,00 & 42,07 & 74,13 & 20,08 & 21,70 & 24,48 & 24,71 & 6,88 & 29,38 \\
\hline $\begin{array}{l}\text { Rio Ouro } \\
\text { Preto }\end{array}$ & $200.560,96$ & $200.561,03$ & $15.994,72$ & 552,70 & 299,34 & 85,86 & 137,46 & 125,63 & 431,93 & 248,86 & 266,03 & 187,20 & 71,87 \\
\hline $\begin{array}{l}\text { Gurupá- } \\
\text { Melgaço }\end{array}$ & $146.365,60$ & $146.365,75$ & $2.195,57$ & 51,59 & & 23,73 & 6,35 & 67,85 & & 6,53 & 57,96 & & 21,23 \\
\hline $\begin{array}{l}\text { Ipaú- } \\
\text { Anilzinho }\end{array}$ & $56.124,95$ & $56.124,96$ & $17.498,91$ & 163,98 & 203,04 & 299,89 & 63,11 & 91,51 & 58,87 & 9,02 & 87,47 & 73,27 & 60,48 \\
\hline Ituxi & $781.396,88$ & $781.397,13$ & $1.083,73$ & 19,32 & 6,42 & 31,00 & 124,26 & 378,91 & 61,87 & 13,82 & 42,33 & 28,62 & 17,57 \\
\hline $\begin{array}{l}\text { Mãe Grande } \\
\text { de Curuçá }\end{array}$ & $38.696,92$ & $22.899,59$ & $1.421,10$ & 15,13 & 36,20 & 21,17 & & & 22,83 & 0,39 & 18,24 & 0,08 & \\
\hline Mapuá & $96.084,24$ & $96.084,32$ & $2.628,76$ & 8,91 & 82,76 & 105,36 & & & 28,35 & & 50,01 & 20,86 & \\
\hline $\begin{array}{l}\text { Marinha } \\
\text { Cuinarana }\end{array}$ & $10.964,62$ & $10.734,85$ & $1.339,41$ & 9,08 & & 8,81 & & & 18,64 & & 7,43 & & 3,58 \\
\hline $\begin{array}{l}\text { Marinha de } \\
\text { Araí-Peroba }\end{array}$ & $62.218,40$ & $33.251,03$ & $4.236,83$ & 12,80 & 13,42 & 11,04 & & & & & 36,95 & & \\
\hline $\begin{array}{l}\text { Marinha } \\
\text { de Caeté- } \\
\text { Taperaçu }\end{array}$ & $42.153,28$ & $24.595,24$ & $2.638,34$ & 16,09 & & & & & & & & & 22,24 \\
\hline $\begin{array}{l}\text { Marinha } \\
\text { de Gurupi- } \\
\text { Piriá }\end{array}$ & $72.468,59$ & $38.291,54$ & $5.908,81$ & 20,96 & 5,86 & & & 7,78 & & & & 0,01 & 7,34 \\
\hline $\begin{array}{l}\text { Marinha de } \\
\text { Soure }\end{array}$ & $29.468,77$ & $21.116,67$ & 544,74 & & 21,11 & 47,17 & & & & & 31,56 & & \\
\hline
\end{tabular}




\begin{tabular}{|c|c|c|c|c|c|c|c|c|c|c|c|c|c|}
\hline $\begin{array}{l}\text { Marinha de } \\
\text { Tracuateua }\end{array}$ & $27.778,48$ & $17.633,78$ & 759,17 & 27,70 & & & & & & & & & \\
\hline $\begin{array}{l}\text { Marinha do } \\
\text { Maracanã }\end{array}$ & $32.063,93$ & $20.903,67$ & $1.338,47$ & 26,92 & 1,64 & 47,20 & 1,87 & 4,72 & 34,32 & & 28,29 & 16,70 & \\
\hline $\begin{array}{l}\text { Marinha } \\
\text { Mestre } \\
\text { Lucindo }\end{array}$ & $27.578,92$ & $17.994,54$ & $1.505,63$ & 50,87 & 19,24 & 6,49 & 1,00 & & 30,43 & 6,50 & 68,17 & 7,24 & \\
\hline $\begin{array}{l}\text { Marinha } \\
\text { Mocapajuba }\end{array}$ & $21.344,47$ & $19.050,55$ & $1.632,15$ & 4,79 & & 11,51 & 21,34 & & & & & & \\
\hline $\begin{array}{l}\text { Médio } \\
\text { Purus }\end{array}$ & $607.204,90$ & $607.204,88$ & $3.988,14$ & 56,99 & 62,53 & 159,12 & 42,46 & 6,47 & 106,22 & 27,80 & 6,83 & 214,58 & \\
\hline Renascer & $211.504,05$ & $211.504,06$ & $12.788,70$ & 887,76 & 277,90 & 479,14 & 196,09 & 119,15 & 244,22 & 142,25 & 600,88 & 206,75 & 431,58 \\
\hline Rio Iriri & $397.900,17$ & $397.900,73$ & $6.480,33$ & 809,24 & 73,74 & & & 18,28 & 11,24 & & 8,51 & & \\
\hline Rio Unini & $846.630,45$ & $846.630,47$ & $1.015,62$ & 14,98 & & 24,26 & 51,78 & & 9,57 & 39,80 & 15,61 & 10,04 & \\
\hline Rio Xingu & $307.506,03$ & $307.505,60$ & $3.523,92$ & 89,29 & & 67,47 & 12,94 & 35,41 & 12,03 & 1,69 & 6,63 & 13,03 & 0,28 \\
\hline $\begin{array}{l}\text { Riozinho da } \\
\text { Liberdade }\end{array}$ & $325.358,63$ & $325.358,67$ & $4.936,78$ & 150,50 & 27,92 & 314,84 & 65,10 & 105,09 & 63,17 & 39,41 & 211,48 & 153,83 & 32,49 \\
\hline $\begin{array}{l}\text { Riozinho do } \\
\text { Anfrísio }\end{array}$ & $739.661,08$ & $739.660,44$ & $2.515,13$ & 137,04 & 330,78 & 107,45 & 99,24 & 167,79 & 19,71 & 240,98 & 221,12 & 119,70 & 170,63 \\
\hline $\begin{array}{l}\text { Tapajós- } \\
\text { Arapiuns }\end{array}$ & $680.769,01$ & $680.772,37$ & $51.138,38$ & 241,17 & 316,82 & 401,20 & 215,68 & 12,77 & 69,70 & 390,98 & 92,72 & 47,94 & 55,63 \\
\hline $\begin{array}{l}\text { Terra } \\
\text { Grande- } \\
\text { Pracuúba }\end{array}$ & $195.618,16$ & $195.618,40$ & $5.845,13$ & & 114,12 & 220,50 & 13,83 & & 62,16 & 7,12 & 16,08 & 67,99 & \\
\hline $\begin{array}{l}\text { Verde para } \\
\text { Sempre }\end{array}$ & $1.290 .119,52$ & $1.290 .119,47$ & $36.579,78$ & $1.169,05$ & $1.812,64$ & $1.317,79$ & 899,33 & 901,48 & 270,89 & 762,96 & $1.533,76$ & 261,13 & 370,82 \\
\hline
\end{tabular}


ANEXO 2 - Desmatamento até 2007, e desmatamento anual de 2008 a 2017, como \% da área total, segundo PRODES 2017 (em \%).

\begin{tabular}{|c|c|c|c|c|c|c|c|c|c|c|c|c|c|}
\hline Nome da UC & $\begin{array}{l}\text { Área da } \\
\text { UC }\end{array}$ & \begin{tabular}{|l|} 
Área \\
total \\
classes
\end{tabular} & $\begin{array}{l}\text { Desmat. } \\
\text { até } 2007\end{array}$ & $\begin{array}{l}\text { Desmat. } \\
2008\end{array}$ & $\begin{array}{l}\text { Desmat. } \\
2009\end{array}$ & $\begin{array}{l}\text { Desmat. } \\
2010\end{array}$ & $\begin{array}{l}\text { Desmat. } \\
2011\end{array}$ & $\begin{array}{l}\text { Desmat. } \\
2012\end{array}$ & $\begin{array}{l}\text { Desmat. } \\
2013\end{array}$ & $\begin{array}{l}\text { Desmat. } \\
2014\end{array}$ & $\begin{array}{l}\text { Desmat. } \\
2015\end{array}$ & $\begin{array}{l}\text { Desmat. } \\
2016\end{array}$ & $\begin{array}{l}\text { Desmat. } \\
2017\end{array}$ \\
\hline $\begin{array}{l}\text { Resex Federais } \\
2017\end{array}$ & $100,00 \%$ & $100,00 \%$ & $2,82 \%$ & $0,07 \%$ & $0,05 \%$ & $0,08 \%$ & $0,04 \%$ & $0,04 \%$ & $0,03 \%$ & $0,05 \%$ & $0,07 \%$ & $0,05 \%$ & $0,04 \%$ \\
\hline Alto Juruá & $100,00 \%$ & $99,96 \%$ & $2,05 \%$ & $0,15 \%$ & & $0,37 \%$ & $0,15 \%$ & $0,06 \%$ & $0,03 \%$ & $0,11 \%$ & $0,02 \%$ & $0,04 \%$ & $0,04 \%$ \\
\hline Arapixi & $100,00 \%$ & $100,00 \%$ & $1,86 \%$ & $0,01 \%$ & $0,04 \%$ & $0,03 \%$ & $0,03 \%$ & $0,01 \%$ & $0,01 \%$ & $0,02 \%$ & $0,04 \%$ & $0,02 \%$ & $0,08 \%$ \\
\hline Arióca-Pruanã & $100,00 \%$ & $100,01 \%$ & $9,50 \%$ & $0,16 \%$ & $0,13 \%$ & $1,35 \%$ & $0,13 \%$ & $0,06 \%$ & $0,07 \%$ & $0,04 \%$ & $0,29 \%$ & $0,12 \%$ & $0,11 \%$ \\
\hline Auatí-Paraná & $100,00 \%$ & $100,09 \%$ & $1,05 \%$ & $0,03 \%$ & $0,01 \%$ & $0,05 \%$ & $0,01 \%$ & & $0,00 \%$ & & $0,01 \%$ & & $0,01 \%$ \\
\hline Barreiro das Antas & $100,00 \%$ & $100,00 \%$ & $0,04 \%$ & $0,01 \%$ & & & & & & & & & \\
\hline Chico Mendes & $100,00 \%$ & $99,99 \%$ & $4,37 \%$ & $0,12 \%$ & $0,04 \%$ & $0,08 \%$ & $0,13 \%$ & $0,13 \%$ & $0,12 \%$ & $0,24 \%$ & $0,35 \%$ & $0,36 \%$ & $0,22 \%$ \\
\hline $\begin{array}{l}\text { Chocoaré - Mato } \\
\text { Grosso }\end{array}$ & $100,00 \%$ & $100,00 \%$ & $8,88 \%$ & & & & & & & & & & \\
\hline Baia do Tubarão & $100,00 \%$ & $2,99 \%$ & $0,05 \%$ & & & & & & $0,02 \%$ & $0,03 \%$ & & & \\
\hline Mata Grande & $100,00 \%$ & $100,00 \%$ & $85,26 \%$ & $1,70 \%$ & $1,53 \%$ & $0,76 \%$ & $0,68 \%$ & $0,74 \%$ & $0,07 \%$ & $0,25 \%$ & $0,33 \%$ & $0,07 \%$ & $0,09 \%$ \\
\hline Arapiranga - Tromaí & $100,00 \%$ & $13,99 \%$ & $8,12 \%$ & & & & & $0,04 \%$ & & & & & \\
\hline Cururupu & $100,00 \%$ & $23,27 \%$ & $34,72 \%$ & $0,05 \%$ & $0,00 \%$ & & & & & $0,01 \%$ & & & \\
\hline Itapetininga & $100,00 \%$ & $100,00 \%$ & $29,57 \%$ & & $0,05 \%$ & & & & & & & & \\
\hline São João da Ponta & $100,00 \%$ & $100,00 \%$ & $4,05 \%$ & $0,28 \%$ & & & & & & $0,00 \%$ & $0,03 \%$ & $0,01 \%$ & \\
\hline Alto Tarauacá & $100,00 \%$ & $100,00 \%$ & $1,82 \%$ & $0,20 \%$ & $0,04 \%$ & $0,21 \%$ & $0,15 \%$ & $0,12 \%$ & $0,01 \%$ & $0,11 \%$ & $0,06 \%$ & $0,03 \%$ & $0,01 \%$ \\
\hline Baixo Juruá & $100,00 \%$ & $100,00 \%$ & $1,42 \%$ & $0,02 \%$ & $0,02 \%$ & $0,02 \%$ & $0,01 \%$ & & $0,01 \%$ & $0,05 \%$ & $0,01 \%$ & $0,01 \%$ & $0,01 \%$ \\
\hline Cazumbá-Iracema & $100,00 \%$ & $100,00 \%$ & $0,94 \%$ & $0,01 \%$ & $0,01 \%$ & $0,04 \%$ & $0,04 \%$ & $0,03 \%$ & $0,03 \%$ & $0,02 \%$ & $0,03 \%$ & $0,04 \%$ & $0,02 \%$ \\
\hline Ciriaco & $100,00 \%$ & $100,00 \%$ & $68,14 \%$ & $1,38 \%$ & $0,66 \%$ & & $0,19 \%$ & & & $0,28 \%$ & $0,08 \%$ & & \\
\hline $\begin{array}{l}\text { Extremo Norte do } \\
\text { Tocantins }\end{array}$ & $100,00 \%$ & $100,00 \%$ & $93,17 \%$ & $0,01 \%$ & & & & & & & & & \\
\hline
\end{tabular}




\begin{tabular}{|c|c|c|c|c|c|c|c|c|c|c|c|c|c|}
\hline $\begin{array}{l}\text { Lago do Capanã } \\
\text { Grande }\end{array}$ & $100,00 \%$ & $100,00 \%$ & $0,97 \%$ & $0,00 \%$ & $0,00 \%$ & $0,09 \%$ & & $0,01 \%$ & & & $0,01 \%$ & $0,00 \%$ & \\
\hline Lago do Cuniã & $100,00 \%$ & $100,00 \%$ & $0,44 \%$ & & & & & & & & & & \\
\hline Médio Juruá & $100,00 \%$ & $100,00 \%$ & $1,18 \%$ & $0,01 \%$ & $0,01 \%$ & $0,01 \%$ & $0,00 \%$ & & $0,01 \%$ & $0,01 \%$ & $0,01 \%$ & $0,01 \%$ & $0,01 \%$ \\
\hline Quilombo Frechal & $100,00 \%$ & $100,00 \%$ & $100,00 \%$ & & & & & & & & & & \\
\hline Rio Cajari & $100,00 \%$ & $100,00 \%$ & $0,61 \%$ & $0,13 \%$ & $0,10 \%$ & $0,03 \%$ & $0,01 \%$ & $0,04 \%$ & $0,02 \%$ & $0,05 \%$ & $0,07 \%$ & $0,03 \%$ & $0,03 \%$ \\
\hline Rio Cautário & $100,00 \%$ & $100,00 \%$ & $0,65 \%$ & & & & & & $0,59 \%$ & & & & \\
\hline Rio Jutaí & $100,00 \%$ & $100,00 \%$ & $0,56 \%$ & $0,04 \%$ & $0,02 \%$ & $0,02 \%$ & $0,03 \%$ & $0,01 \%$ & $0,01 \%$ & $0,01 \%$ & $0,01 \%$ & $0,00 \%$ & $0,01 \%$ \\
\hline Rio Ouro Preto & $100,00 \%$ & $100,00 \%$ & $7,97 \%$ & $0,28 \%$ & $0,15 \%$ & $0,04 \%$ & $0,07 \%$ & $0,06 \%$ & $0,22 \%$ & $0,12 \%$ & $0,13 \%$ & $0,09 \%$ & $0,04 \%$ \\
\hline Gurupá-Melgaço & $100,00 \%$ & $100,00 \%$ & $1,50 \%$ & $0,04 \%$ & & $0,02 \%$ & $0,00 \%$ & $0,05 \%$ & & $0,00 \%$ & $0,04 \%$ & & $0,01 \%$ \\
\hline Ipaú-Anilzinho & $100,00 \%$ & $100,00 \%$ & $31,18 \%$ & $0,29 \%$ & $0,36 \%$ & $0,53 \%$ & $0,11 \%$ & $0,16 \%$ & $0,10 \%$ & $0,02 \%$ & $0,16 \%$ & $0,13 \%$ & $0,11 \%$ \\
\hline Ituxi & $100,00 \%$ & $100,00 \%$ & $0,14 \%$ & $0,00 \%$ & $0,00 \%$ & $0,00 \%$ & $0,02 \%$ & $0,05 \%$ & $0,01 \%$ & $0,00 \%$ & $0,01 \%$ & $0,00 \%$ & $0,00 \%$ \\
\hline $\begin{array}{l}\text { Mãe Grande de } \\
\text { Curuçá }\end{array}$ & $100,00 \%$ & $59,18 \%$ & $6,21 \%$ & $0,07 \%$ & $0,16 \%$ & $0,09 \%$ & & & $0,10 \%$ & $0,00 \%$ & $0,08 \%$ & $0,00 \%$ & \\
\hline Mapuá & $100,00 \%$ & $100,00 \%$ & $2,74 \%$ & $0,01 \%$ & $0,09 \%$ & $0,11 \%$ & & & $0,03 \%$ & & $0,05 \%$ & $0,02 \%$ & \\
\hline Marinha Cuinarana & $100,00 \%$ & $97,90 \%$ & $12,48 \%$ & $0,08 \%$ & & $0,08 \%$ & & & $0,17 \%$ & & $0,07 \%$ & & $0,03 \%$ \\
\hline $\begin{array}{l}\text { Marinha de Araí- } \\
\text { Peroba }\end{array}$ & $100,00 \%$ & $53,44 \%$ & $12,74 \%$ & $0,04 \%$ & $0,04 \%$ & $0,03 \%$ & & & & & $0,11 \%$ & & \\
\hline $\begin{array}{l}\text { Marinha de Caeté- } \\
\text { Taperaçu }\end{array}$ & $100,00 \%$ & $58,35 \%$ & $10,73 \%$ & $0,07 \%$ & & & & & & & & & $0,09 \%$ \\
\hline $\begin{array}{l}\text { Marinha de Gurupi- } \\
\text { Piriá }\end{array}$ & $100,00 \%$ & $52,84 \%$ & $15,43 \%$ & $0,05 \%$ & $0,02 \%$ & & & $0,02 \%$ & & & & $0,00 \%$ & $0,02 \%$ \\
\hline Marinha de Soure & $100,00 \%$ & $71,66 \%$ & $2,58 \%$ & & $0,10 \%$ & $0,22 \%$ & & & & & $0,15 \%$ & & \\
\hline $\begin{array}{l}\text { Marinha de } \\
\text { Tracuateua }\end{array}$ & $100,00 \%$ & $63,48 \%$ & $4,31 \%$ & $0,16 \%$ & & & & & & & & & \\
\hline $\begin{array}{l}\text { Marinha do } \\
\text { Maracanã }\end{array}$ & $100,00 \%$ & $65,19 \%$ & $6,40 \%$ & $0,13 \%$ & $0,01 \%$ & $0,23 \%$ & $0,01 \%$ & $0,02 \%$ & $0,16 \%$ & & $0,14 \%$ & $0,08 \%$ & \\
\hline
\end{tabular}




\begin{tabular}{|c|c|c|c|c|c|c|c|c|c|c|c|c|c|}
\hline $\begin{array}{l}\text { Marinha Mestre } \\
\text { Lucindo }\end{array}$ & $100,00 \%$ & $65,25 \%$ & $8,37 \%$ & $0,28 \%$ & $0,11 \%$ & $0,04 \%$ & $0,01 \%$ & & $0,17 \%$ & $0,04 \%$ & $0,38 \%$ & $0,04 \%$ & \\
\hline $\begin{array}{l}\text { Marinha } \\
\text { Mocapajuba }\end{array}$ & $100,00 \%$ & $89,25 \%$ & $8,57 \%$ & $0,03 \%$ & & $0,06 \%$ & $0,11 \%$ & & & & & & \\
\hline Médio Purus & $100,00 \%$ & $100,00 \%$ & $0,66 \%$ & $0,01 \%$ & $0,01 \%$ & $0,03 \%$ & $0,01 \%$ & $0,00 \%$ & $0,02 \%$ & $0,00 \%$ & $0,00 \%$ & $0,04 \%$ & \\
\hline Renascer & $100,00 \%$ & $100,00 \%$ & $6,05 \%$ & $0,42 \%$ & $0,13 \%$ & $0,23 \%$ & $0,09 \%$ & $0,06 \%$ & $0,12 \%$ & $0,07 \%$ & $0,28 \%$ & $0,10 \%$ & $0,20 \%$ \\
\hline Rio Iriri & $100,00 \%$ & $100,00 \%$ & $1,63 \%$ & $0,20 \%$ & $0,02 \%$ & & & $0,00 \%$ & $0,00 \%$ & & $0,00 \%$ & & \\
\hline Rio Unini & $100,00 \%$ & $100,00 \%$ & $0,12 \%$ & $0,00 \%$ & & $0,00 \%$ & $0,01 \%$ & & $0,00 \%$ & $0,00 \%$ & $0,00 \%$ & $0,00 \%$ & \\
\hline Rio Xingu & $100,00 \%$ & $100,00 \%$ & $1,15 \%$ & $0,03 \%$ & & $0,02 \%$ & $0,00 \%$ & $0,01 \%$ & $0,00 \%$ & $0,00 \%$ & $0,00 \%$ & $0,00 \%$ & $0,00 \%$ \\
\hline $\begin{array}{l}\text { Riozinho da } \\
\text { Liberdade }\end{array}$ & $100,00 \%$ & $100,00 \%$ & $1,52 \%$ & $0,05 \%$ & $0,01 \%$ & $0,10 \%$ & $0,02 \%$ & $0,03 \%$ & $0,02 \%$ & $0,01 \%$ & $0,06 \%$ & $0,05 \%$ & $0,01 \%$ \\
\hline $\begin{array}{l}\text { Riozinho do } \\
\text { Anfrísio }\end{array}$ & $100,00 \%$ & $100,00 \%$ & $0,34 \%$ & $0,02 \%$ & $0,04 \%$ & $0,01 \%$ & $0,01 \%$ & $0,02 \%$ & $0,00 \%$ & $0,03 \%$ & $0,03 \%$ & $0,02 \%$ & $0,02 \%$ \\
\hline Tapajós-Arapiuns & $100,00 \%$ & $100,00 \%$ & $7,51 \%$ & $0,04 \%$ & $0,05 \%$ & $0,06 \%$ & $0,03 \%$ & $0,00 \%$ & $0,01 \%$ & $0,06 \%$ & $0,01 \%$ & $0,01 \%$ & $0,01 \%$ \\
\hline $\begin{array}{l}\text { Terra Grande- } \\
\text { Pracuúba }\end{array}$ & $100,00 \%$ & $100,00 \%$ & $2,99 \%$ & & $0,06 \%$ & $0,11 \%$ & $0,01 \%$ & & $0,03 \%$ & $0,00 \%$ & $0,01 \%$ & $0,03 \%$ & \\
\hline Verde para Sempre & $100,00 \%$ & $100,00 \%$ & $2,84 \%$ & $0,09 \%$ & $0,14 \%$ & $0,10 \%$ & $0,07 \%$ & $0,07 \%$ & $0,02 \%$ & $0,06 \%$ & $0,12 \%$ & $0,02 \%$ & $0,03 \%$ \\
\hline
\end{tabular}

